\title{
LOS DEPÓSITOS DE ARMAS EN EL BRONCE FINAL: UN NUEVO HALLAZGO EN PUERTOLLANO (CIUDAD REAL)
}

\author{
WEAPON HOARD OF THE FINAL BRONZE AGE: A NEW FIND FROM PUERTOLLANO \\ (CIUDAD REAL)
}

\section{MACARENA FERNÁNDEZ RODRÍGUEZ (*) MARÍA JESÚS RODRÍGUEZ DE LA ESPERANZA MANTEROLA (**)}

\section{RESUMEN}

El depósito de espadas de Puertollano (Ciudad Real) ofrece una nueva panorámica sobre las ocultaciones de objetos metálicos. Este depósito en tierra del Bronce Final III, probablemente contó con una señalización externa formada por dos afloramientos de cuarcita. Su situación, carácter exclusivamente armamentístico y coherencia interna hacen que proceda hablar de una ocultación ritual o votiva. Localizado en una zona hasta ahora con escasos hallazgos metálicos, sin embargo, es un área de intenso poblamiento anterior, en donde se conocen poblados, necrópolis y estelas funerarias con la misma cronología que el escondrijo.

\begin{abstract}
The sword hoard from Puertollano (Ciudad Real) presents a new view of the hiding of metal objects. It is possible that this land hoard from the Final Bronze Age III had an external marker made up of two outcrops of quartzite.

Its situation, its exclusively arms nature and its internal coherence make it possible to speak of a ritual or votive concealment. Even though it is located in an area with so farnot many metal finds, it used to be a very densely populated area where we know about the existence of settlements, necropolis and funeral stelae with the same chronology as the hoard.

Palabras clave: Depósito. Armas. Tierra. Votivo. Bronce Final III. Puertollano.

Key words: Hoard. Weapons. Votive. Late Bronze Age III. Puertollano.

(*) Arqueóloga y directora de la excavación del Camino de Santiago. C/Calvario, 16. 13004 Ciudad Real.

(**) Becaria predoctoral Departamento Prehistoria UCM. Facultad de Geografía e Historia. Universidad Complutense. 28040 Madrid.

Recibido: 16-VI-02; aceptado: 17-IX-02.
\end{abstract}

\section{PRESENTACIÓN Y ENTORNO GEOGRÁFICO DEL YACIMIENTO}

\subsection{Presentación}

En este artículo presentamos un yacimiento aparecido en el verano de 2000 en las proximidades de la localidad de Puertollano, en Ciudad Real (Fernández Rodríguez e.p.). Se trata de un conjunto de armas de bronce, cuyo hallazgo fortuito dio lugar a la realización de una excavación de urgencia. En dicha excavación se documentaron algunos restos de cerámica y de industria lítica y se recuperaron varias piezas más de bronce, aunque ninguna estructura.

Las características de los bronces, así como el lugar en el que se localizaron, nos permiten afirmar que se trata de un depósito de armas del Bronce Final Atlántico. El conjunto supone uno de los más importantes de España, en cuanto al número de objetos, ya que cuenta con más de una decena de piezas.

\subsection{Entorno geográfico}

El yacimiento se encuentra situado a unos $5 \mathrm{~km}$ al Sur de Puertollano, en el valle medio del río Ojailén, en la finca 2321, a la que sus propietarios denominan "Camino de Santiago", en una pequeña elevación del terreno. Sus coordenadas geográficas son $38^{\circ} 38^{\prime} 25^{\prime \prime} \mathrm{N}, 0^{\circ} 24^{\prime} 10^{\prime \prime} \mathrm{O}$, según el M.T.N. de escala 1:50.000, hoja $n^{\circ}$ 836: Mestanza (Fig. 1). Está emplazado entre dos cerros de escasa altura: al Oeste el cerro de Buenavista, de $859 \mathrm{~m}$ y al Este un cerrete sin nombre de $749 \mathrm{~m}$ de altitud. Entre ambos discurre un pequeño arroyo -el Tamujoso- afluente por la margen derecha del Ojailén y 


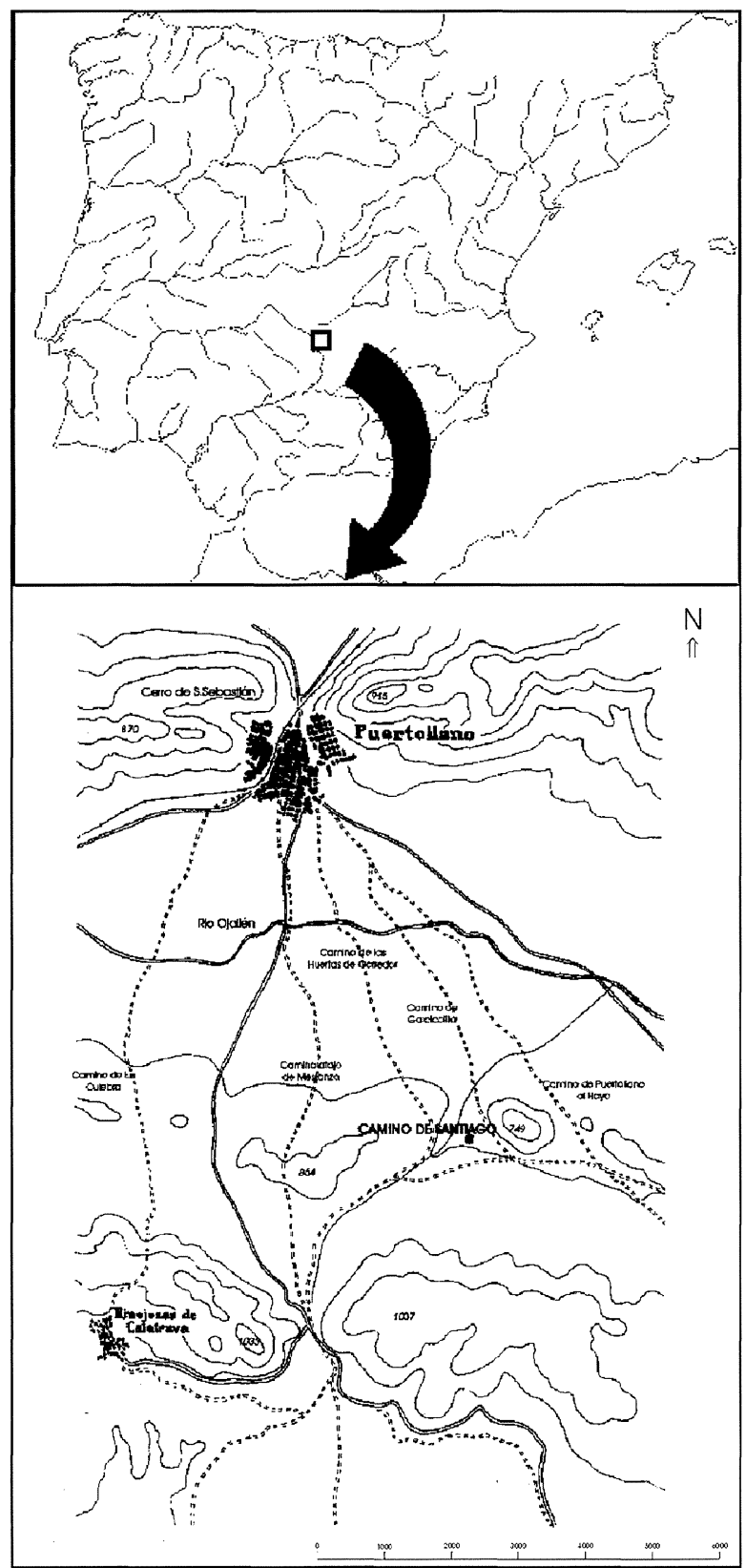

Fig. 1. Situación del yacimiento basado en el M.T.P. escala 1:50.000.

que hoy está prácticamente seco. Próximo a él, y a unos $100 \mathrm{~m}$ del yacimiento, existe un pozo de agua, todavía en uso. Algunos metros más abajo, en el cerro de Buenavista, se localiza un depósito de aguas (Sánchez y García Cáceres 1989).

El Ojailén es un río de escasa longitud, apenas $80 \mathrm{~km}$, que vierte sus aguas al Fresnedas, colector del Montoro, perteneciente a la cuenca del Guadal- quivir. Su valle está delimitado al Norte por la Sierra de Calatrava, con los cerros de Santa Ana y San Sebastián, entre los que se sitúa Puertollano, y por el Sur la Sierra que lleva este mismo nombre y que lo separa del valle de Alcudia, importante punto de destino de las rutas de transhumancia tradicionales.

En torno a este río se sitúa la industria minera de Puertollano y un poderoso complejo industrial, por lo que el paisaje actual está compuesto por escombreras y pozos antiguos, minas a cielo abierto, industrias eléctricas y petroquímica. Junto al yacimiento todavía perviven pequeñas explotaciones agrícolas destinadas al cultivo de huertas y cereal $\mathrm{y}$ al pasto del ganado vacuno. Las zonas de sierra, de mayor altitud y pendiente, están cubiertas por un espeso monte. Algunas de estas fincas hoy sólo se utilizan como segunda residencia de los habitantes de Puertollano, muchos de los cuales acuden a la "Dehesa Boyal", situada a unos $2 \mathrm{~km}$ en dirección Suroeste, como lugar de recreo y esparcimiento.

Esta zona es un importante punto de paso, a medio camino entre los puertos de Mestanza y puerto del Roble al Sur, que lo comunica con el valle de Alcudia y el puerto de Puertollano, al Norte, que le enlaza con el Campo de Calatrava, en el valle del Guadiana. Así lo atestiguan la red de caminos y cañadas que lo cruzan en dirección Norte-Sur/ SurNorte y Este-Oeste. Pero a su vez era lugar de destino de algunos de estos caminos.

Por la mitad occidental del Ojailén discurre una cañada, que enlaza con otra procedente del Sur, y, continúa hacia el Norte por Puertollano. Esta cañada coincide, en parte, con el trazado de la carretera nacional 420. De ella parten una colada, que sigue la corriente del río hacia el Este, y dos cordeles en dirección Sur. Estos últimos cruzan la Sierra de Puertollano, una por el puerto de Mestanza, paralela en parte a la carretera que conduce hacia Mestanza, y otra por el puerto de los Robles, hasta enlazar con otro cordel que sigue el cauce del río Montoro en dirección a Andalucía. Esta última se encuentra a escasos metros del yacimiento (1). Esta tupida red de cañadas, cordeles y coladas, muestra la importancia de la ganadería en esta zona, que a partir del siglo XVI se convierte en la actividad económica más importante, junto a la industria de paños y a una minería variable y anómala (Ramírez

(1) El trazado de las vías pecuarias está tomado el Mapa Provincial de Ciudad Real de escala 1:200.000 publicado por la Consejería de Agricultura de la Junta de Comunidades de Castilla-La Mancha. Toledo, 1992.

T. P., 59, n. ${ }^{\circ} 2,2002$ 
1995: 38), hasta la explotación de las minas de carbón en el último tercio del siglo XIX.

En la actualidad, el yacimiento se encuentra en una encrucijada de caminos que parten de Puertollano hacia el Sur: a unos $50 \mathrm{~m}$ al Oeste, coincidiendo en parte con el arroyo de Tamujoso, pasa el "camino de las Huertas de Corredor", y a unos $200 \mathrm{~m}$ al Este el "camino de Puertollano al Hoyo", ambos unidos por otro camino que parte del primero en dirección Este, hacia el Villar y que pasa a unos 20 $\mathrm{m}$ del yacimiento.

\subsection{Entorno arqueológico}

Las sierras de Calatrava, al Norte del río Ojailén, y la de Puertollano, al Sur, están repletas de yacimientos arqueológicos, que son apenas conocidos y que han sido escasamente estudiados. Las noticias que tenemos sobre ellos son bastante imprecisas, pero sirven para determinar al menos su existencia. El conjunto lo integran en torno a una veintena de yacimientos, entre estaciones de pintura rupestre esquemática (Puente Natural, El Dolmen, La Ventana, El Chorrero, Peñón del Aguila 1 y 2, El Mirador, Las Láminas, Cueva de la Estación, Collado de la Olla de las Vacas y Puerto de Mestanza), poblados de altura (Navalromo, El Frangil, Cerro de San Sebastián, Cerro de Santa Ana, Los Castillares) y covachas o supuestas estructuras funerarias (Cueva de los Murciélagos, covachas en el Puerto de Mestanza), que han sido adscritas al periodo comprendido entre el Calcolítico y el Bronce Final (González Ortíz 1989a y b).

En el mismo valle del Ojailén y a escasos metros del "Camino de Santiago", se localiza sobre el cerro de Buenavista, a $859 \mathrm{~m}$ de altitud, un yacimiento del Bronce Final (2).

\section{CIRCUNSTANCIAS DEL HALLAZGO Y EXCAVACIÓN ARQUEOLÓGICA}

El hallazgo se produjo de forma fortuita, mientras una excavadora preparaba el terreno para pavimentar el suelo y hacer una terraza delante de una casa de campo. Junto a ella había dos afloramientos de cuarcita, uno de los cuales había sido utilizado con anterioridad como poyete. La máqui-

(2) Información facilitada por Francisco Javier Lópiez Fernández, que prospectó esta zona al hacer el seguimiento del Gasoducto. na picó la roca y se encontraba excavando parte del terreno cuando los dueños detectaron la presencia de cuatro objetos metálicos entre sus dientes. Inmediatamente detuvieron la pala y comenzaron a rebuscar, primero entre la tierra removida y más tarde en la terrera, donde encontraron cinco piezas más. Tras paralizar la obra, informaron del descubrimiento al Ayuntamiento de Puertollano y a la Consejería de Cultura de la Junta de Comunidades de Castilla-La Mancha. Días más tarde, los dueños del terreno decidieron interrumpir las obras indefinidamente hasta conocer la decisión de las autoridades y rellenaron con tierra la zona excavada para que nadie pudiera identificar el sitio. Las piezas fueron trasladadas al Museo Provincial de Ciudad Real, en donde se encuentran en estos momentos.En las semanas siguientes los técnicos responsables realizaron varias visitas al yacimiento, en una de las cuales se hallaron en superficie un hacha de piedra y una moledera activa, y aconsejaron la realización de una excavación arqueológica de urgencia.

Una vez localizado el lugar del hallazgo, cuya superficie era de unos $32 \mathrm{~m}^{2}$, se abrieron cinco cortes, separados por testigos, cuatro de ellos situados delante de la casa, donde presumiblemente salieron las armas, y el quinto ubicado al Sur de los anteriores, en el lugar donde aparecieron el hacha y la moledera de piedra. La dimensión de los mismos era de 2 por $4 \mathrm{~m}$ en los cuatro primeros y de 2 por 2 el último. Su orientación es Norte-Sur y van paralelos a la casa de campo, de la que distan únicamente 10-20 cm (Fig. 2). Por último, se excavó la terrera, emplazada en la parte trasera de la casa, a la que se le denominó corte 6 . Los testigos fueron desmontados al finalizar la excavación.

El sistema de trabajo empleado fue el de levantamiento de planos artificiales de unos $10 \mathrm{~cm}$, separándose los contextos mediante números de inventario. Se tomaron las coordenadas de todos ellos y se situaron sobre un plano escala 1:20.

Las cuadrículas 1 y $\mathbf{5}$, las más próximas a la puerta de acceso a la vivienda, fueron totalmente estériles. Se documentaron dos niveles distintos, el superficial estaba formado por una capa de arena de unos 5-10 cm de espesor. El inferior lo constituía un estrato de tierra marrón con restos de ladrillos, aluminio, cristales y cemento, bajo el que aparecía la roca madre, constituida por cuarcita, claramente cortada y machacada.

El corte 2 tiene similares características. La roca se sitúa a unos $30 \mathrm{~cm}$ bajo el suelo actual. La capa 


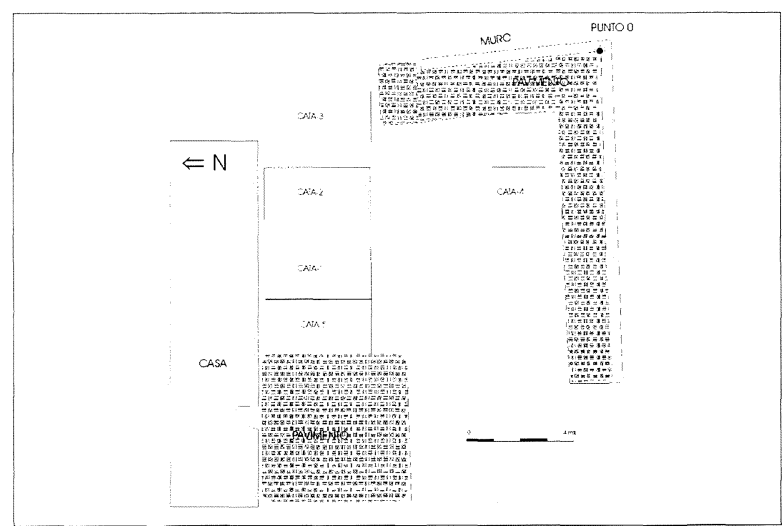

Fig. 2a. Planimetría de la excavación.
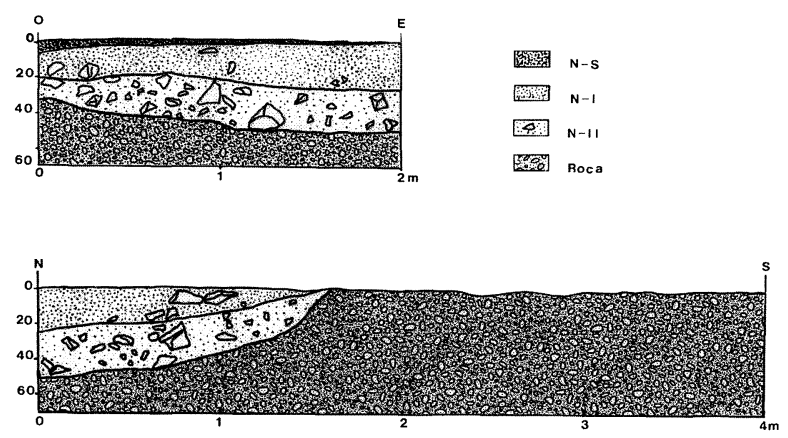

Fig. 2b. Perfiles Norte y Este del Corte 3.

más superficial estaba formada por un relleno de arena y bajo ella aparecía un estrato de tierra marrón claro con material de revuelto. En el extremo meridional de la cuadrícula se documentó una vértebra de animal, probablemente reciente; en la parte central y en el contacto entre ambos niveles, apareció un fragmento de espada de bronce. En la parte septentrional del corte, junto a la pared de la casa, la tierra era más oscura y húmeda. Aquí se localizaron varios fragmentos de cerámica a mano, dos piezas de silex y una lasca de cuarcita.

La cuadrícula 3, situada al Este de las anteriores, fue la más fructífera. Tenía escasa profundidad y la cuarcita afloraba en gran parte de su superficie. Sin embargo, en el extremo nororiental, se documentó una pequeña zona intacta, en torno a $4 \mathrm{~m}^{2}$, con la siguiente secuencia:

- Nivel Superficial formado por una capa estéril de arena de unos 6-8 cm.

- Nivel I, de 20 a $25 \mathrm{~cm}$ de espesor, según las zonas, compuesto por tierra marrón oscura con pocas piedras y abundante cerámica. Esta estaba muy fragmentada y se deshacía al tocarla. Casi toda se encontraba a la misma cota, a unos $25-30 \mathrm{~cm}$ bajo el suelo actual.

- Nivel II, con espesor variable de 10 a $25 \mathrm{~cm}$, lo integra una tierra marrón clara con muchas piedras. Es estéril y asienta sobre la roca madre.

La cuadrícula 4 se localiza al Sur de la cata 2, de la que dista 4,5 m. En esta zona no intervino la máquina excavadora, pero en sus proximidades se habían realizado varios agujeros para la plantación de árboles. Se excavaron tres niveles de unos $10 \mathrm{~cm}$ cada uno. La tierra no presentaba variaciones y era de color marrón rojiza, con algunas piedras sueltas. En el nivel I aparecieron un regatón de bronce y varios fragmentos de cerámica antigua y moderna. El resto de los niveles fueron estériles.

Paralelamente al trabajo de excavación se procedió al desmonte de la terrera -corte 6-, cuyas dimensiones eran de unos $6 \mathrm{~m}$ de largo por $5 \mathrm{~m}$ de ancho y $0,9 \mathrm{~m}$ de alto. Estaba formada piedras mezcladas con tierra y basura (plásticos, aluminios, vidrios, hierros, ladrillos, latas, etc.). Las piedras eran de distintos tamaños, grandes, medianas y pequeñas, procediendo la mayor parte de ellas de la roca madre, que había sido previamente fracturada y rota por la máquina. En esta terrera se recuperaron nueve objetos de bronce, de los cuales tres son espadas, uno un puñal y el resto fragmentos de espadas.

\section{DESCRIPCIÓN DE LAS ARMAS}

El depósito está formado por 10 espadas, 4 puñales, 1 regatón y 3 fragmentos de empuñaduras de espadas. Las espadas tienen un tamaño inferior al normal -en torno a los $30 \mathrm{~cm}$ de media- que las sitúa en la categoría de puñales-espadas más que en la de espadas propiamente dicha. Sólo una de ellas, a la que le falta la mitad de la hoja, tendría un tamaño sensiblemente superior, en torno a los $70-90 \mathrm{~cm}$. $\left(\mathrm{n} .{ }^{\circ} 4\right)$. Todas pertenecen al tipo de lengua de carpa. Ninguna de las piezas conserva las cachas, que debieron ser orgánicas.

Los puñales corresponden a espadas reutilizadas. En todos los casos se ha prescindido de la empuñadura original y se ha tomado únicamente la hoja, en la que se han practicado dos o cuatro hendiduras, según los casos, para facilitar el nuevo enmangue. Dos pueden ser clasificados como tipo "Porto de Mos" (Fig. 5: 7 y 8) y otros dos corresponden a amortizaciones de espadas de lengua de carpa (Fig. 5: 5 y 6). 
- Espada n. ${ }^{1}$ : Espada de lengua de carpa (Fig. 3.1)

- Sigla: 260/001.

- Pomo: En forma de pez.

- Puño: Ligeramente convexo con calado central rectangular.

- Guarda: Con un calado a cada lado. En forma de V.

- Lengüeta/ricassos: Bien marcados y limitados por muescas.

- Hoja: Estrecha, con pequeño ensanchamiento en la parte distal. Nervio central de sección circular definido por dos acanaladuras que nacen en la guarda. Hoja ligeramente pistiliforme.

- Filos: Paralelos, con bordes erosionados.

- Punta: Estrechamiento progresivo que remata en lengua de carpa.

- Conservación: Buena. La pieza está entera, salvo las cachas y los remaches de sujeción de las mismas. Tiene ligeras deformaciones en los filos. En algunas zonas presenta aspecto pulverulento, debido a la falta de consistencia de la patina.

- Longitud: $336 \mathrm{~mm}$.

- Anchura máxima guarda: $52 \mathrm{~mm}$.

- Anchura hoja: $36 \mathrm{~mm}$ junto a los ricassos y 25 en la parte central.

- Grosor máximo: $7 \mathrm{~mm}$.

- Peso: 159,03gr.

- Espadan. ${ }^{\circ}$ : Espada de lengua de carpa. (Fig. 3.2)

- Sigla: 260/002.

- Pomo: No conservado.

- Puño: Ligeramente convexo, roto en la parte superior. Tiene calado central rectangular.

- Guarda: Exvasada, con dos calados laterales. En forma de V.

- Lengüeta/ricassos: Cortos, limitados por muescas.

- Hoja: Nervio central, más grueso en la parte distal, definido por dos acanaladuras que nacen en la guarda. Hoja ligeramente pistiliforme.

- Filos: Paralelos, cortantes, con muescas laterales y pequeños dobleces. Puede apreciarse en la zona de la punta unos biseles marcando lo que pudiera ser un reavivado del filo.

- Punta: Estrechamiento progresivo para rematar en lengua de carpa.

- Conservación: Falta la cacha y el pomo está partido. Falta la terminación. En la fractura tiene agujeros de aire, uno de los cuales abarca prácticamente toda la sección, que es triangular. Presenta los bordes erosionados y mellados.

- Longitud máxima: $293 \mathrm{~mm}$.
- Anchura máxima guarda: $50 \mathrm{~mm}$.

- Anchura máxima hoja: $31 \mathrm{~mm}$.

- Grosor máximo: $10 \mathrm{~mm}$.

- Peso: 175 gr.

- Espadan. 3: Espada de lengua de carpa (fig. 3.3).

- Sigla: 260/003.

- Empuñadura: No conserva las cachas orgánicas.

- Pomo. No conservado.

- Puño: Sólo se conserva la parte inferior. Calado central, posiblemente rectangular.

- Guarda: Exvasada, con dos calados laterales. En forma de v.

- Lengüeta/ricassos: No muy profundos, limitados por muescas muy pronunciadas.

- Hoja: Nervio central de sección circular, que se ensancha en la parte distal, definido por dos acanaladuras. El extremo final está roto y doblado. Hoja ligeramente pistiliforme.

- Filos: Paralelos; bordes erosionados y doblados por uno de sus lados. Puede apreciarse en la zona de la punta unos biseles marcando lo que pudiera ser un reavivado del filo.

- Punta: Estrechamiento progresivo rematado en lengua de carpa. Está doblada y rota.

- Conservación: Fractura elástica en la parte de la punta, justo por el lugar donde ésta se dobla. Presenta los bordes con pequeñas muescas. El pomo está partido y falta la terminación.

- Longitud máxima: $308 \mathrm{~mm}$

- Anchura máxima guarda: $49 \mathrm{~mm}$.

- Anchura máxima hoja: $33 \mathrm{~mm}$.

- Peso: 190 gr.

- Espada n. 4: Espada de lengua de carpa (fig. 3.4).

- Sigla: 260/004.

- Pomo: En forma de pez.

- Puño: Ligeramente convexo, con calado central rectangular.

- Guarda: Exvasada, con dos calados laterales. En forma de v.

- Lengúeta/ricassos: Bien marcados y limitados por muescas.

- Hoja: Nervio central de sección circular con dos acanaladuras, que nacen en la guarda. Fracturada e incompleta en la parte distal.

- Filos: rectos y paralelos, doblados por uno de los lados en la parte superior.

- Punta: no se conserva.

- Conservación: Falta la cacha, aunque presenta la empuñadura prácticamente completa; el extre- 


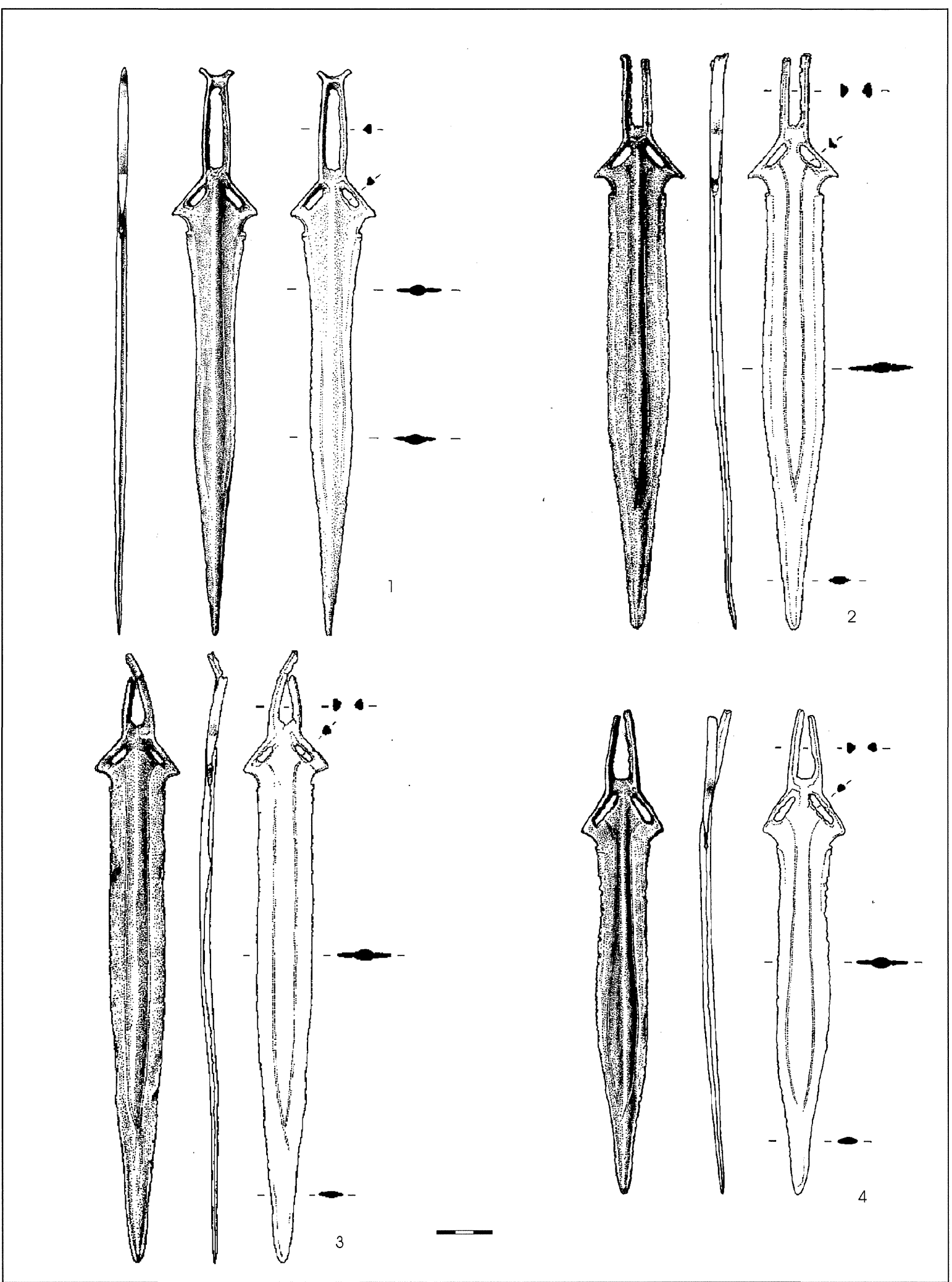

Fig. 3. Espadas del depósito de Puertollano.

T. P., 59, n. ${ }^{\circ} 2,2002$ 
mo izquierdo del pomo está muy gastado. Falta un trozo considerable de la punta. Tiene textura rugosa. Presenta muchos agujeros de aire en el puño, que casi lo atraviesan de lado a lado y que muestran que por algunos lados está casi hueco.

- Longitud máxima: $310 \mathrm{~mm}$.

- Anchura máxima guarda: $57 \mathrm{~mm}$.

- Anchura máxima hoja: $39 \mathrm{~mm}$ junto a la guarda y 29 en el resto.

- Grosor máximo: $8 \mathrm{~mm}$.

- Peso: 290 gr.

- Espada n. 5: Espada de lengua de carpa (fig. 4.1).

- Sigla: 260/005.

- Pomo: No se conserva.

- Puño: Incompleto y doblado en la parte superior. Calado central rectangular.

- Guarda: Exvasada, con dos calados laterales. En forma de v.

- Lengüeta/ricassos: Curvos, bien marcados, limitados por muescas ligeramente pronunciadas.

- Hoja: Reforzada por nervadura axial de sección circular, con dos acanaladuras laterales que arrancan de la guarda.

- Filos: Paralelos, con pequeñas muescas.

- Punta: Estrechamiento progresivo para rematar en lengua de carpa. Presenta biseles marcando lo que pudiera ser un reavivado del filo.

- Conservación: Bastante buena. La pieza está entera, salvo la parte terminal de la empuñadura, rota y deformada, como también lo están los filos de la hoja, que presentan pérdidas de pátina.

- Longitud máxima: $367 \mathrm{~mm}$.

- Anchura máxima guarda: $51 \mathrm{~mm}$.

- Anchura máxima hoja: $33 \mathrm{~mm}$.

- Grosor máximo: $8 \mathrm{~mm}$.

- Peso: 220 gr.

- Espada n. ${ }^{\circ}$ : Espada de lengua de carpa (Fig. 4.2).

- Sigla: 260/006.

- Pomo: No conservado.

- Puño: Ancho y recto, con calado central rectangular. Está roto antes de llegar al pomo y presenta agujeros de aire en la fractura, que en uno de los lados casi lo atraviesa. de v.

- Guarda: Con dos calados laterales. En forma

- Lengüeta/ricassos: Marcados, cóncavos, limitados por muescas pronunciadas. Al hacer los ricassos no se limaron los resaltas resultantes.

- Hoja: Recta, de nervio central con sección circular, con acanaladuras laterales que nacen en la guarda. Hoja ligeramente pistiliforme.

- Filos: Paralelos, con ligero ensanchamiento en la parte inferior y bordes con muescas laterales (erosionados). Puede apreciarse en la zona de la punta unos biseles marcando lo que pudiera ser un reavivado del filo de unos $5 \mathrm{~mm}$ de anchura.

- Punta: Estrechamiento progresivo para rematar en lengua de carpa.

- Conservación: Buena. Faltan las cachas, el pomo, parte del puño y los remaches. La hoja está ligeramente doblada hacia la derecha.

- Longitud máxima: $346 \mathrm{~mm}$.

- Anchura máxima guarda: $54 \mathrm{~mm}$.

- Anchura máxima hoja: $37 \mathrm{~mm}$.

- Grosor máximo: $7 \mathrm{~mm}$.

- Peso: 230 gr.

- Puñal, n. ${ }^{\circ}$ 7: Puñal tipo "Porto de Mos" (fig.5.8).

- Sigla: 260/007 y 260/001.

- Empuñadura: Independiente de la hoja, no conservada. La parte final termina en recto y sigue mostrando el nervio central, lo que demuestra que se trata de una pieza reutilizada.

- Lengüeta/ricassos: Lengüeta de enmangue con dos entalladuras laterales para sujetar la hoja, la superior mucho más pronunciada que la inferior. Tiene dos orificios para remache, que no atraviesan la pieza por completo. Los ricassos aparecen a 12 $\mathrm{mm}$ los primeros y a $31 \mathrm{~mm}$ los segundos. Están limados por ambos lados de la hoja.

- Hoja: Nervio central de sección circular, con acanaladuras laterales, que se prolongan hasta el final de la pieza.

- Filos: Paralelos, ligeramente entrantes en la parte central, muy homogéneos y sin escotaduras.

- Punta: Estrechamiento anterior, que termina bruscamente en la punta.

- Conservación: Presenta una pátina noble, estable y protectora que da lugar a una superficie uniforme, con pequeñas manchas negras y pequeñas picaduras. Falta la cacha. Buen estado del núcleo metálico. La parte de la empuñadura, hasta por debajo de los ricassos está más oscura.

- Longitud máxima: $196 \mathrm{~mm}$.

- Anchura máxima hoja: $28 \mathrm{~mm}$.

- Grosor máximo: $5 \mathrm{~mm}$.

- Peso: 125 gr.

- Puñal n. ${ }^{\circ}$ 8: Puñal en lengua de carpa (fig.5.5)

- Sigla: 260/002. 


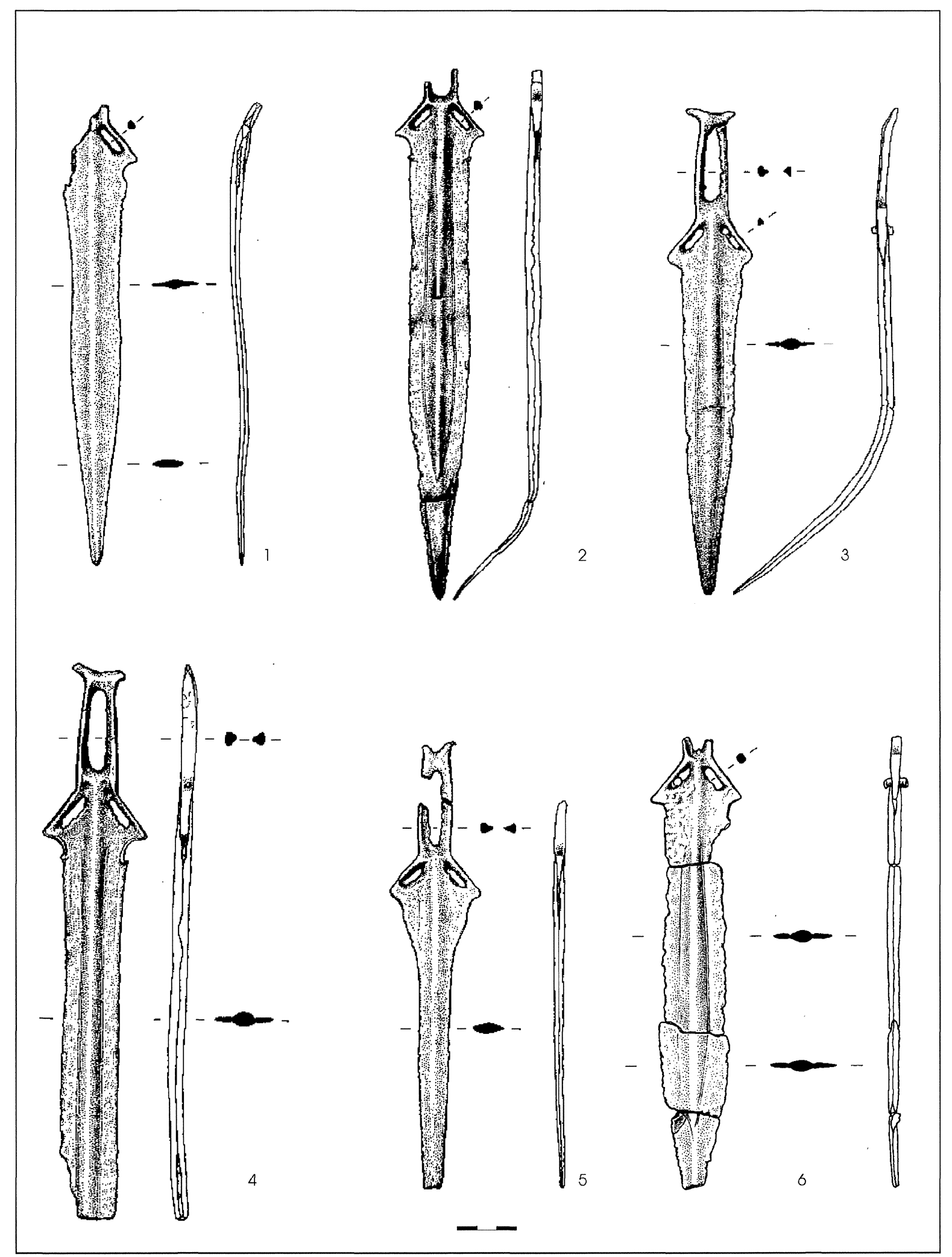

Fig. 4. Espadas del depósito de Puertollano.

T. P., 59, n. $^{\circ} 2,2002$ 

dida.

- Empuñadura: Independiente de la hoja, per-

- Lengüeta/ricassos: Lengüeta pseudocircular con extremo superior recto y dos escotaduras -una a cada lado- que marcan el comienzo de la hoja. Las escotaduras están bastante limadas y son asimétricas.

- Hoja: Nítidamente diferenciada de la lengüeta, con nervio axial ligeramente definido en la hoja y flanqueado por dos acanaladuras, que acaban en los ricassos.

- Filos: Convergentes, con poco desgaste y poco cortantes.

- Punta: Estrechamiento progresivo rematado en lengua de carpa.

- Conservación: Presenta una pátina noble, estable y protectora, que da lugar a una superficie uniforme, pulverulenta en aquellas zonas donde se forma una capa negra más oscura y esponjosa. Tiene una pequeñísima grieta en la parte central del extremo distal de la hoja, junto a la punta. En ésta última presenta una coloración más oscura.

- Longitud máxima: $260 \mathrm{~mm}$.

- Anchura máxima hoja: $33 \mathrm{~mm}$.

- Grosor máximo: $5 \mathrm{~mm}$.

- Peso: 170 gr.

- Puñal n. 9: Puñal (Fig. 5.6).

- Sigla: 260/009 y 260/003.

- Empuñadura: Independiente de la hoja, no conservada.

- Lengüeta/ricassos: Lengüeta de enmangue con dos entalladuras en cada lateral para asegurar el mango. Las entalladuras son bastante irregulares, asimétricas y de distinto tamaño y están bien limadas.

- Hoja. Nítidamente diferenciada de la lengüeta, con nervio axial, desplazado del centro, flanqueado por acanaladuras laterales poco marcadas. Presenta un estrechamiento en la parte mexial.

- Filos: Desgastados, con pequeñas muescas.

- Punta: Estrechamiento progresivo rematado en lengua de carpa. El extremo final es romo.

- Conservación: Presenta deformaciones y ligeras pérdidas en los filos de la hoja, así como una profunda grieta en la parte distal de la misma, que ocupa tres cuartas partes de su ancho. Tiene pátina noble, estable y protectora, que da lugar a una superficie uniforme, con pequeñas manchas negras y pequeñas picaduras.

- Longitud máxima: $263 \mathrm{~mm}$.

- Anchura máxima hoja: $31 \mathrm{~mm}$.
- Grosor máximo: $5 \mathrm{~mm}$.

- Peso: 140gr.

- Espada n. ${ }^{\circ}$ 10: Espada de lengua de carpa (fig. 4.6).

- Sigla: 101/502/505/601.

- Empuñadura: Incompleta. No conserva el pomo ni el puño. Guarda con dos calados laterales. En el de la derecha conserva un remache, que no tiene cabeza y parece estar cortado o limado por sus extremos

- Lengúeta/ricassos: No muy marcados, limitados por muescas.

- Hoja: Relativamente ancha, con nervio central de sección circular, más ancho en el tercio inferior, flanqueado por acanaladuras que apenas se aprecian en la zona de la guarda. Está fragmentada de antiguo en tres trozos. Hoja ligeramente pistiliforme.

- Filos: Páralelos, con ensanche en el tercio inferior de la hoja y muescas laterales (bastante mellados).

- Punta: Estrechamiento en lengua de carpa, poco acentuado. No conserva el extremo final.

- Conservación: Está fragmentada en cuatro trozos y le falta el pomo, casi todo el puño y la punta. La superficie es rugosa y porosa, con pátina verde y marrón por la tierra, ya que está sin limpiar, tal como se halló en la excavación. Las fracturas no muestran agujeros de aire, como en otras piezas. En el extremo final de la hoja, próxima a la punta presenta una grieta muy profunda, que casi la atraviesa en sentido oblicuo.

- Longitud máxima: $253 \mathrm{~mm}$.

- Anchura guarda: $49 \mathrm{~mm}$.

- Anchura máxima hoja: $38 \mathrm{~mm}$.

- Grosor máximo: $7 \mathrm{~mm}$.

- Peso: 170gr.

- Espada n. ${ }^{\circ}$ 11: Espada de lengua de carpa (fig. 4.3).

- Sigla: 510.

- Pomo: En forma de pez. Más corto el extremo derecho.

- Puño: Recto, con calado rectangular.

- Guarda: Con dos calados alargados. El derecho conserva un remache. En forma de v.

- Lengúeta/ricassos: No muy marcados, cortos, limitados por muescas poco pronunciadas.

- Hoja: Con nervio central de sección circular con pequeño ensanchamiento en el tercio inferior; está rodeado por dos acanaladuras, apenas percep- 
tibles en la zona de la guarda. Está doblada por la mitad, hacia la izquierda.

- Filos: Paralelos, con muescas y doblado por algunos lados.

- Punta: Estrechamiento progresivo que remata en lengua de carpa no muy marcada.

- Conservación: Le falta el extremo final de la punta, que parece estar cortada. La hoja se dobla hacia la mitad. Presenta tres grietas, una junto al pomo, que casi lo atraviesa, otra en el centro de la hoja, donde ésta se dobla, que atraviesa el nervio central y la última, más pequeña y menos profunda, a unos $34 \mathrm{~mm}$ más debajo de la anterior. Tiene muy gastada la acanaladura central del mango.

- Longitud máxima: $310 \mathrm{~mm}$.

- Anchura guarda: $46 \mathrm{~mm}$.

- Anchura máxima hoja: $33 \mathrm{~mm}$ junto a ricassos, $28 \mathrm{~mm}$ en el resto.

- Grosor máximo: $6 \mathrm{~mm}$.

- Peso: 180 gr.

- Espada n. ${ }^{\circ}$ 12: Estoque (fig. 4.5).

- Sigla: 501.

- Pomo: En forma de pez.

- Puño: Alargado, con calado central rectangular. En forma de v.

- Lengüeta/ricassos: Cortos y no muy marcados.

- Hoja: Muy estrecha, con nervio central, que nace en la guarda, sin acanaladuras.

- Filos: Muy estrechos, paralelos, homogéneos y sin escotaduras.

- Punta: No se conserva.

- Pátina: Verde muy oscuro. Con pequeñas manchas de color claro.

- Conservación: El puño apareció seccionado en dos, con fractura reciente, y le falta de antiguo un pequeño trozo del pomo y la punta que, a juzgar por la rotura ligeramente cóncava, parece que estaba doblada.

- Longitud máxima: $249 \mathrm{~mm}$.

- Anchura guarda: $49 \mathrm{~mm}$.

- Anchura máxima hoja: $17 \mathrm{~mm}$.

- Grosor máximo: $6 \mathrm{~mm}$.

- Peso: 120 gr.

- Espada n. 13: Espada de lengua de carpa (fig. 4.4).

- Sigla: 509.

- Empuñadura: Incompleta. No conserva ni el pomo, ni el puño y sólo tiene la mitad de la lengüeta y los ricassos.

T. P., 59, n. $^{\circ} 2,2002$
- Lengüeta/ricassos: Curvos, limitados por muecas. El de la izquierda no se conserva.

- Hoja: Estrecha, con ligero ensanchamiento en el tercio inferior y nervio central sin acanaladuras. Hoja ligeramente pistiliforme.

- Filos: Paralelos. Sin muescas ni dobladuras.

- Punta: Estrechamiento progresivo para rematar en lengua de carpa.

- Conservación: Presenta superficie rugosa. Le falta casi toda la empuñadura y tiene una grieta en la zona de unión de las dos acanaladuras de la guarda, que la atraviesa casi por completo. La hoja está ligeramente doblada.

- Pátina: Marrón, pulverulenta, con restos de tierra.

- Longitud máxima: $258 \mathrm{~mm}$.

- Anchura máxima hoja: $28 \mathrm{~mm}$.

- Grosor máximo: $10 \mathrm{~mm}$.

- Peso: 140 gr.

- Puñal, n. ${ }^{\circ}$ 14: Puñal (fig.5.6).

- Sigla: 508.

- Empuñadura: Independiente de la hoja, perdida.

- Lengúeta/ricassos: Falta la lengüeta. Se conservan sólo dos escotaduras laterales, una a cada lado, que son poco profundas, en torno a $3 \mathrm{~mm}$, pero parece que pudo tener cuatro, si bien las dos de la parte inferior apenas son hoy perceptibles. El extremo final es recto y parece cortado.

- Hoja: Ancha. Nervio central marcado, ligeramente más ancho en la parte mexial, que se prolonga hasta el final de la empuñadura; está rodeado por dos acanaladuras. La hoja ha sido recortada y progresivamene estrechada para su enmangue.

- Filos: Paralelos, con muescas laterales. Mellados, con pequeñas muescas.

- Punta: Progesivo estrechamiento rematado en lengua de carpa.

- Conservación: Presenta una pequeñísima grieta horizontal, ligeramente curva, en el centro del extremo distal, junto a la punta.

- Pátina: Marrón clara, pulverulenta. Está cubierta de tierra.

- Longitud máxima: $235 \mathrm{~mm}$.

- Anchura máxima hoja: $33 \mathrm{~mm}$.

- Grosor máximo: $5 \mathrm{~mm}$.

- Peso: 97,7 gr.

- Regatón, $n .^{\circ} 15$ (fig. 5.4).

- Sigla: 301. 


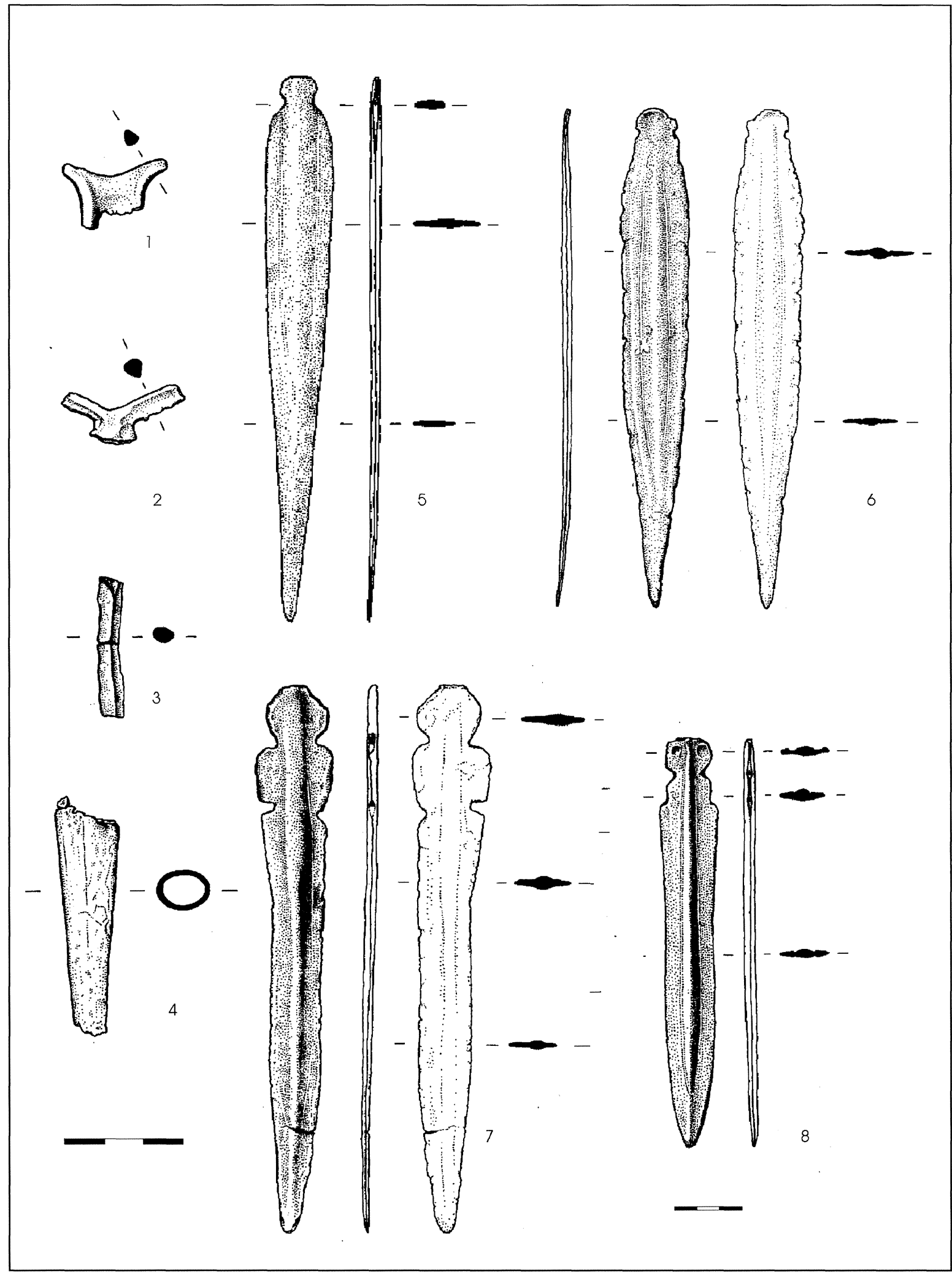

Fig. 5. Fragmentos y puñales del depósito de Puertollano 
- Forma: Forma tubular. No conserva los agujeros del remache.

- Remaches: No conservados

- Remate: No conservado. El extremo final es macizo, está relleno de metal.

- Conservación: Está incompleto por los dos extremos. En la parte superior presenta escotaduras y una grieta vertical que se prolonga hasta aproximadamente la mitad de la pieza. Tiene pequeñas marcas o líneas verticales, a modo de pequeñísimas incisiones, que recuerdan la textura de un hueso. La superficie exterior es muy suave.

- Pátina: Verde brillante.

- Longitud máxima conservada: $60 \mathrm{~mm}$.

- Grosor máximo conservado: $17 \mathrm{~mm}$.

- Peso: 15,5 gr.

- Fragmento de espada, $n .^{\circ} 16$ (fig.5.3).

- Sigla: 602.

- Descripción: Fragmento de bronce de forma alargada, de sección pseudotriangular. Probablemente perteneciente al puño de una espada.

- Conservación: Está roto por sus dos extremos y presenta una grieta profunda, que casi lo atraviesa por la mitad.

- Longitud máxima conservada: $38 \mathrm{~mm}$.

- Grosor: $6 \mathrm{~mm}$.

- Peso: 4,5 gr.

- Fragmento de espada, $n .^{\circ} 17$ (fig.5.1).

- Sigla: 503.

- Descripción: Fragmento de empuñadura de espada. Sólo se conserva el pomo, en forma de pez y el arranque del puño.

- Conservación: Está roto por la parte inferior, en la parte del puño. Las fracturas son poco limpias y en uno de sus extremos, el más corto, el interior está completamente hueco, por un agujero de aire. Los extremos del pomo están desgastados.

- Longitud máxima conservada: $26 \mathrm{~mm}$.

- Anchura: $28 \mathrm{~mm}$.

- Grosor: $7 \mathrm{~mm}$.

- Peso: 5,6 gr.

- Fragmento de espada, $n^{\circ} 18$ (fig. 5.2).

- Sigla: 506.

- Descripción: Fragmento de bronce en forma de $\mathrm{V}$ muy abierta. Los extremos superiores tienen sección triangular y la parte inferior, donde se juntan los anteriores, es maciza, de forma pseudooval. Se trata del fragmento de contacto entre el puño y la guarda. La única espada que carece de esta zona es la número 13, sin embargo ni la disposición del ángulo, ni la composición del metal (3) encajan. Esto hace pensar en la existencia de alguna otra pieza más, con una disposición de enmangue parecida a la espada 3.

- Conservación: Está roto de antiguo por sus tres extremos, pero las fracturas son limpias y uniformes, sin agujeros de aire. (Las fracturas son antiguas.)

- Longitud máxima conservada: $18 \mathrm{~mm}$.

- Anchura: $33 \mathrm{~mm}$.

- Grosor: $6 \mathrm{~mm}$.

- Peso: 5,5gr.

\section{LOS PUÑALES}

Cuatro ejemplares son clasificados como puñales por sus dimensiones y por su forma $(7,8,9$ y 14). La tipología de, al menos, dos de ellos coincide con los puñales tipo Porto de Mos ( 7 y 9), aunque están muy deteriorados, y en uno de los casos (n. ${ }^{\circ}$ ), , parece tener su origen en una pieza reaprovechada más antigua, quizás de una espada tipo Rosnöen o, en una espada de lengua de carpa. En ambos casos el nervio central no está lo suficientemente marcado como para dividir longitudinalmente la hoja en dos. Sin embargo, los dos ejemplares tienen el nervio central marcado y los filos paralelos, características propias de este tipo y que se presenta antes en los puñales que en las espadas (Fernández García 1997: 99-100). El puñal n. ${ }^{\circ} 9$ se asemeja bastante a uno de la Ría de Huelva (Ruiz-Gálvez 1995: lámina 10-6), y a otro localizado en Hinojedo, perteneciente al denominado "Línea Porto de Mos" por Fernández García (1998: 100).

El otro ejemplar (n..$^{\circ}$ ) es un puñal completo tipo Porto de Mos con las líneas muy marcadas y del que podemos encontrar paralelos en el propio depósito de la Ría de Huelva (Ruiz Gálvez 1995: 241, 1-8). Es el puñal más pequeño y puede ser clasificado como Porto de Mos con empuñadura Ballintober (Fernández García 1997; Rowlands 1976), aunque por lo marcado de sus hombros podríamos decir que tendría paralelos en los de Vènat (Coffyn et al. 1981). Briard y Mohen sitúan los puñales de lengüeta trapezoidal o rectangular, que forman con los hombros ángulos y no esco-

(3) Así lo demuestran los análisis metalográficos realizados en el Centro Nacional de Aceleradores de Sevilla cuyos resultados se darán a conocer en un artículo de I. Montero y M. Fernández, actualmente en prensa 
taduras, en el Bronce Final Atlántico III (950-750 a.C) (Ruíz-Gálvez 1998: 208), pues aparecen en aquel depósito de Vénat y en el de la Prairie de Mauves (Mantes, Loire-Atlantique)(Fernández García 1997: 106) y nosotras consideramos que esta cronología es acertada para este puñal de Puertollano.

Los puñales $n .^{\circ} 8$ y n. ${ }^{\circ} 14$ pertenecen a espadas de "lengua de carpa" reutilizadas -con la posibilidad de que también hubiesen podido pertenecer a una espada tipo Rosnöen- cuya parte distal de la hoja fue reaprovechada, dada las características de la hoja, muy alargada y puntiaguda, y de que la decoración que marca el nervio central se pierde en lo que podríamos denominar el cuello del enmangue, donde se ajustaría la empuñadura. Además las acanaladuras dispuestas a ambos lados del nervio central tienen continuación en la parte del estrechamiento de la guarda, lo que también nos indica que se trata de una reutilización.

El puñal que menos se adecua a estas descripciones y paralelos es el que tiene la hoja más triangular y cuya empuñadura acaba en dos muescas o $r i-$ cassoi $\left(n .^{\circ} 8\right)$ muy diferentes a lo que hasta ahora hemos descrito. Tal y como decíamos en nuestra opinión el ejemplar pertenecería también a la amortización de la hoja de una espada tipo lengua de carpa de largas dimensiones, cuya empuñadura símplemente se ha realizado a base del estrechamiento para situar dos remaches a cada uno de los lados. La prolongación del engrosamiento del nervio observable en la empuñadura corrobora la hipótesis de que se trata de una reamortización.

De los cuatro puñales, el $\mathrm{n}^{\circ}{ }^{\circ} \mathrm{y}$ el $\mathrm{n}^{\circ} 8$ son los que se conservan mejor, observándose unos filos sin deterioro aún tratándose uno de ellos, el n. ${ }^{\circ} 8$, de una reamortización. El que hemos clasificado como "Línea Porto de Mos" (n. ${ }^{\circ}$ 9), se encuentra en peor estado, distinguiéndose mal sus diferentes partes y teniendo grietas en la hoja (seguramente debidas a una mala desgasificación durante su producción) lo que nos indica que tuvo un uso considerable o que sufrió durante los procesos postdeposicionales. Este puñal también procede de una reamortización de la hoja de una espada, en este caso de una espada de transición pistiliforme/lengua de carpa; dado que el nervio continúa más allá del fin de la empuñadura y que se aprovecha el ensanchamiento de la hoja pistiliforme para trabajar allá la empuñadura con los calados para los remaches.

Los puñales tienen un peso y dimensiones semejantes, excepto el n. ${ }^{\circ} 7$ que con una longitud de
$196 \mathrm{~mm}$, se desvía de la media de los otros tres ejemplares en torno a los $250 \mathrm{~mm}$.

\section{LAS ESPADAS DE TIPO "LENGUA DE CARPA" Y DE TRANSICIÓN PISTILIFORMES/LENGUA DE CARPA}

El conjunto en sí, tiene muchas similitudes con el depósito de la Ría de Huelva (Ruiz Gálvez 1984 y 1987), con la salvedad del menor númeró de ejemplares, de que no tiene tanta variedad y de que presentan un tamaño más reducido. La coherencia interna del depósito, ya tratada en el apartado anterior, la tipología de los ejemplares y sus paralelos en la Península (Almagro 1940; López Palomo 1978; Ruiz Delgado 1988), hacen que se pueda plantear la hipótesis de su posible pertenencia a un taller autóctono, que penetrase hacia la Submeseta Sur desde la fachada atlántica donde estaría su ámbito de incidencia. La localización del depósito, en un punto de paso esencial para el ganado entre la Meseta Norte y la Meseta Sur, y en una zona próxima a valles que comunican de Oeste a Este el Sur de la Península Ibérica, apoyaría la tesis de Ruíz Gálvez que indica que los depósitos o atesoramientos aparecen en lugares o puntos de comunicación claves durante el mundo del Bronce Final (Ruíz Gálvez 1995) (Figs. 6 y 7).

La descripción de las espadas cortas, y de la espada, atiende a unas características generales que se adecúan perfectamente a la tipología general de este tipo del Bronce Final Atlántico (Coffyn 1985; Ruiz Gálvez 1995, Vilaseca 1993). El pomo, en forma de cola de pez se ha conservado completo en dos de los puñales/espadas. Este pomo aún no es recto como ocurrirá paulatinamente en los ejemplares del Norte de Europa, sino que tiene una suave forma de $\mathrm{U}$ abierta. La guarda de todas ellas es exvasada y tiene dos calados laterales que tienden a medir en torno a 1,7-2 cm. La lengüeta o ricassos esta limitada por dos muescas laterales, aún no muy pronunciadas pero que remarcan el comienzo de la hoja. Precísamente la lengüeta está más marcada en el ejemplar n. ${ }^{\circ} 4$ que es el que supuestamente perteneció a una espada en lengua de carpa completa.

Existe una proporcionalidad evidente entre las dimensiones máximas de la guarda y el estrechamiento del ricassos que, aproximadamente coinciden con la proporción de 3/5 (ricassos/guarda). Sin embargo, no se puede decir que la anchura de la hoja mantenga proporciones fijas puesto que, en 


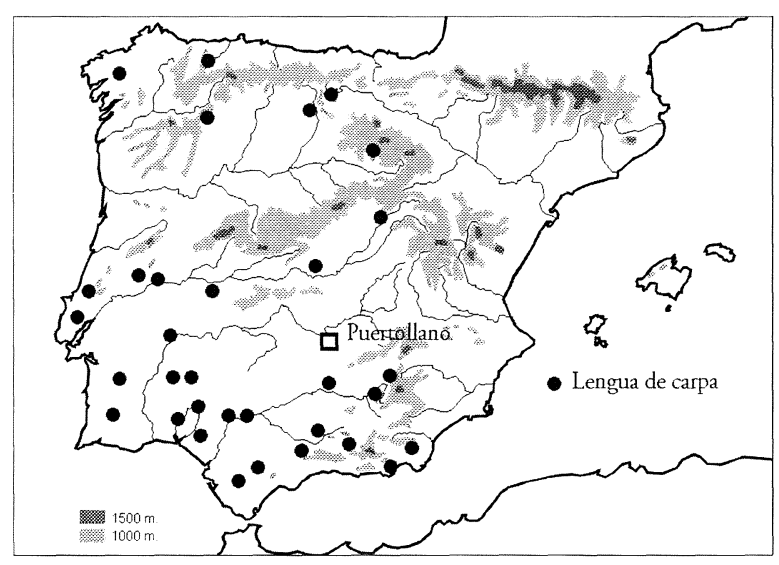

Fig. 6. Dispersión de las espadas en lengua de carpa del Bronce Final Atlántico en la Península Ibérica (basado en Almagro Gorbea 1989).

nuestro conjunto, varía desde unos milímetros más estrechas que el ricassos, hasta unos milímetros más anchas que el mismo, no superando, en ningún caso, los ocho milímetros de diferencia respecto de la lengüeta. Estas dimensiones se relacionan directamente con la resistencia a los impactos que debe aguantar un arma de estas características.

Las hojas de estas piezas tienen un nervio central, a veces marcado por una arista que puede estar decorada o tener una acanaladura, y cuya función era introducir aire en la herida del enemigo con el fin de que sangrase más. Los filos de las espadas de este conjunto son de dos tipos: 1.- Paralelos hasta el comienzo del estrechamiento de la punta que se acusa hasta formar la "lengua de carpa" que da nombre al tipo y 2.- Convergentes con un ensanchamiento mesial que de nuevo se extrecha y que da lugar a las hojas pistiliformes o pistiliformes de transición lengua de carpa cuando esta forma no es demasiado acusada. La punta se ha conservado en siete $\left(\mathrm{n} .{ }^{\circ \mathrm{s}} 1,2,3,5,6,11, \mathrm{y} 13\right)$ ejemplares y es esbelta y alargada.

La pieza $n .^{\circ} 12$ parece ser una reutilización de una espada del mismo tipo lengua de carpa en lo que sería un estoque de hoja mucho más alargada y estrecha. Este tipo de estoques aparecen durante el llamado Bronce Final III (Briard y Mohen 1983: 176).

En conjunto la conservación es buena, aunque necesita de un tratamiento de restauración (4). Sólo

(4) En la actualidad todas ellas están siendo restauradas por la Junta de Comunidades de Castilla-La Mancha en la Escuela de Restauración de Toledo.

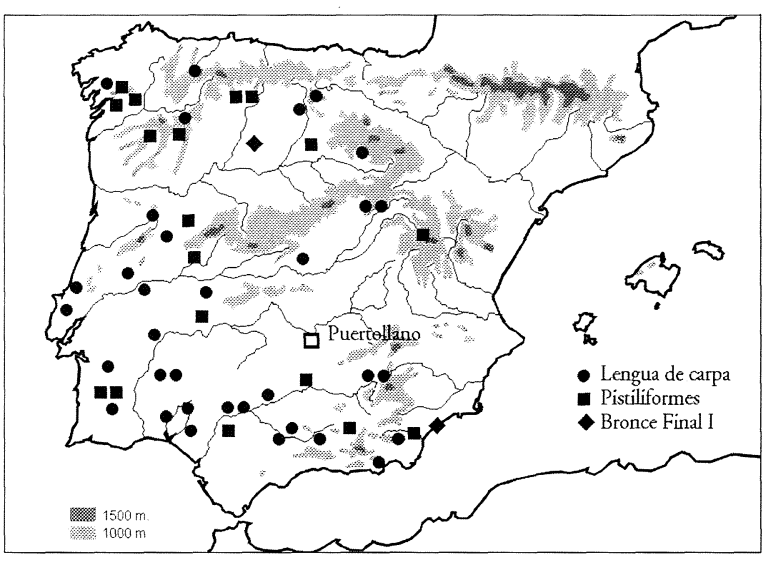

Fig. 7. Dispersión de las espadas en lengua de carpa, pistiliformes y del Bronce Final I con respecto al depósito de Puertollano (basado en Almagro Gorbea 1989).

dos de las fracturas que aparecen en las espadas se deben a las propias circunstancias del descubrimiento (n. ${ }^{\circ} 3$ y n. $\left.{ }^{\circ} 12\right)$ y el resto corresponden a roturas antiguas.

Tres pomos (n. ${ }^{\circ s} 16,27$ y 18) aparecieron fragmentados, con fractura antigua y sin asociación a las propias armas, y un cuarto, de fractura reciente, se asocia con seguridad al estoque $-n .^{\circ} 13-$, que lo había perdido.

\begin{tabular}{|l|l|l|l|l|l|}
\hline Tipo & No Invent. $^{\text {Peso(gr.) }}$ & Long. máx. & Anch. máx. & $\begin{array}{l}\text { Grosor } \\
\text { máx. }\end{array}$ \\
\hline Espada & 1 & 159 & 305 & 25 & 7 \\
\hline Espada & 2 & 175 & 293 & 31 & 10 \\
\hline Espada & 3 & 190 & 308 & 33 & ¿? \\
\hline Espada & 4 & 290 & 310 & 29 & 8 \\
\hline Espada & 5 & 220 & 367 & 33 & 8 \\
\hline Espada & 6 & 230 & 346 & 37 & 7 \\
\hline Espada & 10 & 170 & 253 & 38 & 7 \\
\hline Espada & 11 & 180 & 310 & 28 & 6 \\
\hline Espada & 12 & 120 & 249 & 17 & 6 \\
\hline Espada & 13 & 140 & 258 & 28 & 1 \\
\hline Puñal & 7 & 125 & 196 & 28 & 5 \\
\hline Puñal & 8 & 170 & 260 & 33 & 5 \\
\hline Puñal & 9 & 140 & 263 & 31 & 5 \\
\hline Puñal & 14 & 97,7 & 235 & 33 & 5 \\
\hline Regatón & 301 & 15,5 & & & \\
\hline Media & \multicolumn{7}{|l|}{} \\
\hline Mediana & \multicolumn{7}{|l|}{} \\
\hline
\end{tabular}

Total peso aproximado depósito* $2561 \mathrm{gr}$.

Tab. 1. Pesos y medidas del depósito de Puertollano. Los fragmentos no se contabilizan para evitar distorsiones en los valores medios de medidas y pesos.

En cuanto a pesos y medidas podemos decir que existe una cierta homogeneidad interna dentro de este subgrupo de armas del Depósito de Puertolla-

T. P., 59, n. ${ }^{\circ} 2,2002$ 
no. La media de los pesos es de 187 gr (máximo de 290 gr. y mínimo de 120 gr.) y la de las medidas es de 230-305 mm. Sin embargo, debemos aclarar que esta media esta tomada incluyendo los ejemplares fracturados. Curiosamente, incluso con las armas fracturadas, se aprecia esta cierta homogeneidad en las medidas, lo que nos lleva a pensar que quizás las fracturas no fueron arbitrarias o que las armas fueron elegidas para su depósito ex profeso por sus dimensiones longitudinales. Sin embargo, mientras las dimensones de las espadas cortas se mantienen dentro de unos cánones, no ocurre lo mismo con los pesos que difieren hasta en 170 grs.

\section{PARAlelos}

Como ya indicábamos el conjunto tiene semejanzas muy evidentes con el Depósito de Huelva en general y con alguno de sus ejemplares en concreto, además de con otras piezas de la Península Ibérica.

Entre los puñales hemos encontrado los siguientes paralelos tipológicos con la Ría:

- Puñal $n^{\circ}{ }^{\circ}$, se asemeja algo a la pieza de la Ría de Huelva al n. ${ }^{\circ}$ (de la lám 11, p. 241 (RuizGalvez 1995: 240, lám.10). Depósito de Vénat (Coffyn et al. 1981).

- Puñal n. ${ }^{9}$ 9, semejante al ${ }^{\circ} 10$ (Ruiz-Galvez 1995: 240, lám. 10).

- Puñal n. ${ }^{\circ} 8$, semejante al $\mathrm{n}^{\circ} 12$ de la lám. 10 (Ruiz-Galvez 1995: 240, lám. 10).

- Puñal n. ${ }^{\circ}$ 14, semejante a los n ${ }^{\circ} 13,14$ y 20 de la lám. 10 , p. 240 . Recuerda también al $\mathrm{n}^{\circ} 7$ de la lám. 14 (Ruiz-Galvez 1995: 240, lám. 10), pero el de Puertollano no tiene perforaciones.

De las espadas, las más parecidas a las de Puer-

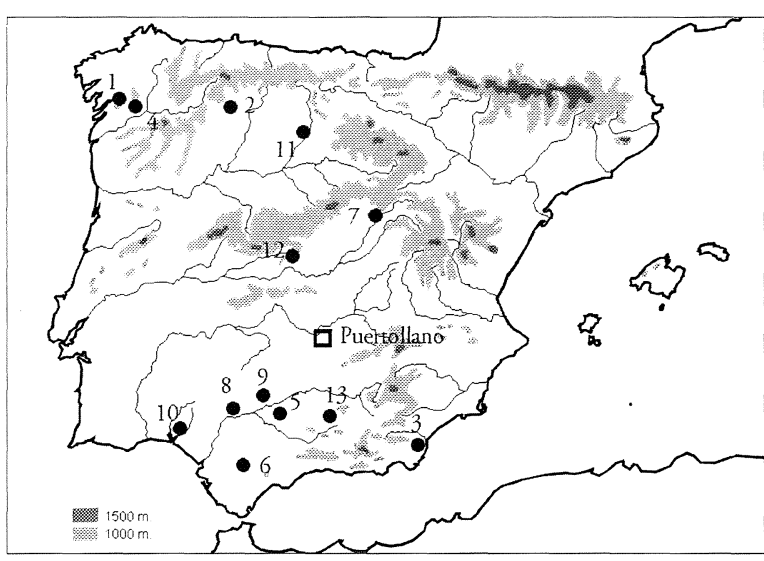

Fig. 8. Localización en la Península Ibérica de los ejemplares más semejantes a las espadas cortas de Puertollano (Ciudad Real): 1. Río Ulla (Pontevedra); 2. Río Esla (León); 3. Tabernas (Almería); 4. Santa María de Oleiros (Pontevedra); 5. Río Genil (Sevilla); 6. Bornós (Cádiz); 7. Sigüenza (Guadalajara); 8. Arroyo Blanco (Sevilla); 9. Palma del Río (Córdoba); 10. Ría de'Huelva (Huelva); 11. Frechilla (Palencia); 12. Carpio de Tajo (Toledo); 13. Carcabuey (Córdoba).

tollano son las de Palma del Río, en Frechilla, Palencia (Fernández 1986: fig. 29 2) y dos procedentes del Depósito de Huelva (Ruiz Gálvez 1995: 240, lám. 1012 2), no sólo por su tipología, sino por sus reducidas dimensiones, más próximo a las pequeñas piezas de Puertollano.

Las características tipológicas de las espadas cortas, semejantes a las de la Ría de Huelva, de los dos puñales tipo Venat y del regatón de cobre que a continuación describiremos, así como del depósito en su conjunto, nos hace pensar en una cronología del Bronce Final III, en torno al 950 a.C. Esta cronología concuerda perfectamente con la establecida por dataciones C-14 en el Depósito de la Ría de Huelva.

\begin{tabular}{|l|c|c|c|c|c|c|c|c|}
\hline Paralelos & $\begin{array}{c}\text { Ría de } \\
\text { Huelva }\end{array}$ & Tabernas & $\begin{array}{c}\text { Arroyo } \\
\text { Blanco }\end{array}$ & $\begin{array}{c}\text { Palma del } \\
\text { Río }\end{array}$ & Almería & Segovia & Sigüenza & Bornós \\
\hline Espada 1 & $\mathbf{x}$ & $\mathbf{x}$ & $\mathbf{x}$ & $\mathbf{x}$ & $\mathbf{x}$ & & & $\mathbf{x}$ \\
\hline Espada 2 & $\mathbf{x}$ & $\mathbf{x}$ & $\mathbf{x}$ & $\mathbf{x}$ & $\mathbf{x}$ & & & $\mathbf{x}$ \\
\hline Espada 3 & $\mathbf{x}$ & $\mathbf{x}$ & $\mathbf{x}$ & $\mathbf{x}$ & $\mathbf{x}$ & $\mathbf{x}$ & & $\mathbf{x}$ \\
\hline Espada 4 & $\mathbf{x}$ & & & & & & $\mathbf{x}$ & \\
\hline Espada 5 & $\mathbf{x}$ & & & & & & & \\
\hline Espada 6 & $\mathbf{x}$ & & & & & & & \\
\hline Espada 7 & & & & & & & & \\
\hline Espada 8 & & & & & & & & \\
\hline Espada 9 & & & & & & & & \\
\hline Espada 10 & $\mathbf{x}$ & $\mathbf{x}$ & $\mathbf{x}$ & $\mathbf{x}$ & $\mathbf{x}$ & & & $\mathbf{x}$ \\
\hline
\end{tabular}

Tab. 2. Paralelos de las espadas en lengua de carpa del depósito de Puertollano. 


\section{EL FRAGMENTO DE REGATÓN}

Se trata de un regatón casi completo cuya sección tubular es muy semejante a los ejemplares del depósito de Huelva (Ruiz Gálvez 1995: 247). Según los análisis de composición esta pieza es de cobre (Montero y Fernández, e.p.), lo que le convierte en un caso excepcional, ya que todos los hasta ahora analizados son de bronce. Los regatones son elementos de la panoplia ofensiva que suelen ser habituales en los depósitos del Bronce Final, por lo que encajaría perfectamente en un depósito de estas características.

\section{CERÁMICA}

La cerámica hallada no encaja dentro del conjunto del depósito puesto que sus características pertenecen a cronologías anteriores. En total se recuperaron algo más de un centenar de piezas, muy rodadas y fragmentadas. Hay muy pocos fragmentos que den forma. Se trata de bordes exvasados de sección almendrada, claramente clasificable en el Calcolitico Final del Suroeste (Rodríguez Díaz y Enriquez Navascués 2001: 59), bordes entrantes y bordes rectos (Fig. 9). Las pastas son groseras, de colores rojo o negruzco, con predominio de coc-

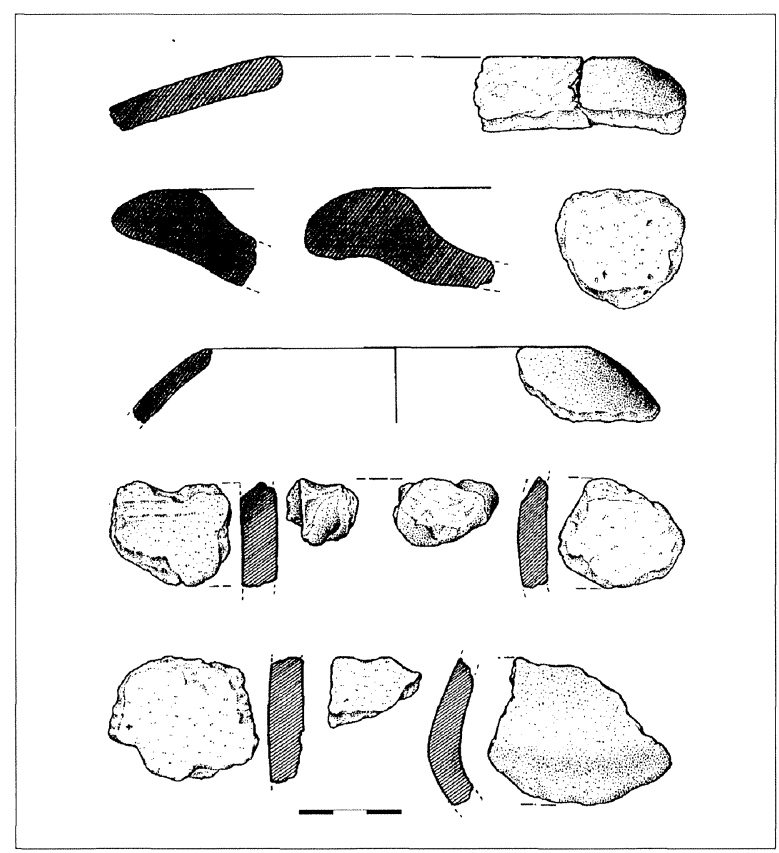

Fig. 9. Cerámica a mano procedente de la excavación de "El Camino de Santiago".

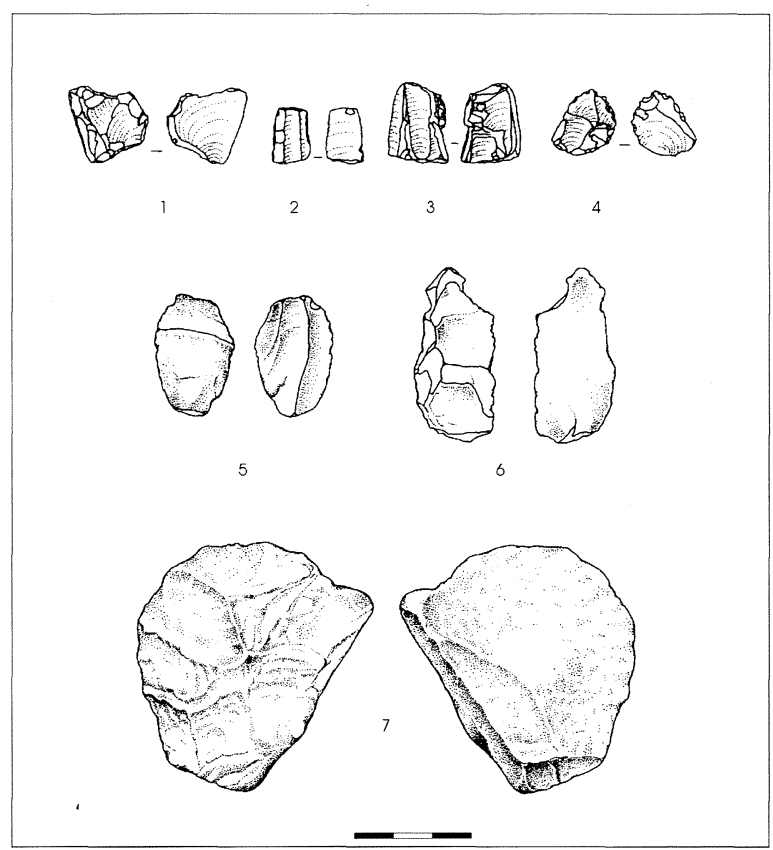

Fig. 10. Industria lítica. Útiles de sílex y cuarcita.

ción mixta aunque también encontramos fragmentos de cocción oxidante y reductora. Los desgrasantes son medios/gruesos y son de origen mineral (cuarcita, caliza, cuarzo, mica...) y orgánicos (carbón, pajas).

\section{INDUSTRIA LÍTICA}

Está compuesta por 4 piezas de sílex y 3 de cuarcita. En cuanto a los sílex, presentan distintas características, tanto por su color, como por su tipología. Los n. ${ }^{\circ} 1$ y 3 (Fig. 10) corresponden a lascas; el primero de color gris oscuro y el segundo de color miel. El n. ${ }^{\circ} 2$ es una pequeña laminita de color también melado y el n. ${ }^{\circ} 3$ se trata de un núcleo de silex rojo, del que parecen haberse extraído pequeñas laminillas. Las otras son dos lascas y un posible buril de cuarcita. Por otra parte, debemos incluir en el conjunto un hacha de piedra pulimentada y una moledera activa, que aparecieron en superficie, en la zona situada entre los cortes 3 y 4 (Fig. 11). Esta industria lítica coincide cronológicamente con los materiales cerámicos y no parece plausible poderla asociar a los materiales metálicos del depósito del Bronce Final. 


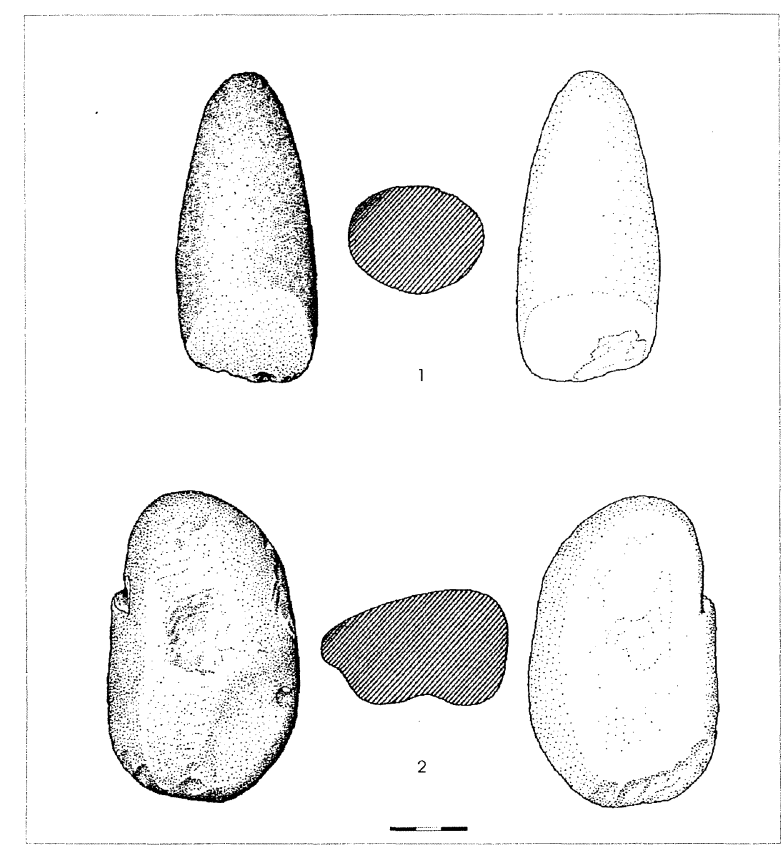

Fig. 11. Hacha y moledera de piedra halladas en superficie.

\section{INTERPRETACIÓN DEL DEPÓSITO DE PUERTOLLANO Y SU RELACIÓN ARQUEOLÓGICA CON EL ENTORNO}

El depósito del Bronce Final III de Puertollano es en cuanto al número de espadas el segundo en importancia en España, después del de la Ría de Huelva. Sin embargo, entre uno y otro hay notables diferencias: su aparición en tierra y en agua respectivamente, el carácter exclusivamente defensivo del primero y con matices de prestigio del segundo y el tamaño de las espadas, más pequeño en Puertollano que en Huelva.

El lugar del hallazgo del depósito manchego es muy significativo. Se encuentra en el paso natural de la Meseta Norte a la Meseta Sur, justo donde confluye el Valle de Alcudia, vía natural de comunicación entre el Suroeste y el Sureste, en donde se sitúan las famosas minas de Almadén.

No debemos olvidar que, además, una de las vías Norte-Sur pasa muy cerca de las minas de cobre de Cerro Muriano (Córdoba) (Domergue 1991). Asimismo, los yacimientos de Alarcos, a unos $40 \mathrm{~km}$ al Norte del depósito y de La Bienvenida, a la misma distancia, hacia el Suroeste, son lugares que se vienen relacionando, por las características de los materiales cerámicos, con los de la Alta Andalucía y la zona del Suroeste (Fernández et al. 1995; Zarzalejos et al. e.p.).
La situación del yacimiento en un paso natural tan significativo no parece ser casual, sea cual sea el motivo de la ocultación (amortización, comercio, ritual, etc.). La homogeneidad de las aleaciones broncíneas de las espadas y puñales (Montero y Fernández 2002) y de sus tamaños lleva a pensar que se trata de un depósito perteneciente probablemente a un solo taller, por lo que cabría deducir que todas ellas o la mayoría se fundieron en el mismo ámbito: relacionado con el Suroeste de la Península y el mundo Atlántico del Bronce Final. Las espadas parecen pertenecer a un mismo estilo, incluso a una misma forma de tratamiento de los bronces, aunque las diferencias entre las propias espadas del depósito nos sugiere una evolución y diferentes artesanos (v. 1, 3, 10, y 11). Tan sólo el puñal n. ${ }^{\circ} 7$, tipo "Porto de Mos", tiene una factura y un material diferente. Este parece tener además mayor masa y, por lo tanto, diferente composición y factura que los demás (5). La presencia de este puñal, en perfecto estado de conservación en un depósito así, plantea algunos interrogantes $¿$ Responde a una ocultación de piezas armamentísticas con el fin de recuperarlas posteriormente? ¿Pertenecieron acaso al depósito de un artesano metalúrgico?

Algunos aspectos que han sido planteados con anterioridad, merecen una explicación más detenida. En realidad no se puede decir que ningún arma haya sido hecha por el mismo artesano sin un estudio metalográfico que ofrezca un criterio de manufactura homogéneo. Cuando se habla de talleres de metalúrgicos nos referimos a un amplio concepto de taller, es decir: tradiciones en la forma de realizar los objetos de metal. No podemos saber si las piezas con las hojas pistiliformes fueron realizadas por un mismo artesano o no, pero sí se observa que responden a un mismo estilo o tipo, aunque los calados de los ejemplares son diferentes y las empuñaduras no se desarrollan de la misma forma. Por otra parte, la evolución nos la proporciona la propia presencia de espadas de transición pistiliforme/ lengua de carpa y las auténticas lengua de carpa.

Sobre la finalidad de la ocultación existen varias posibilidades con una orientación ritual. Podría tratarse de un marcador de caminos como sugieren algunos autores (Ruiz Gálvez 1995) en casos similares. Apoyando esta idea tendríamos el hecho de su ubicación en una zona de paso ganadera, relativamente proxima a las estelas decoradas de Aldea del

(5) Los análisis metalúrgicos han demostrado que la composición, aún siendo similar, es diferente al resto (Montero y Fernández 2002). 
Rey, Hinojedo, Alamillo y del Viso, con las habituales representaciones de espadas y que, estas a su vez, se relacionan con las de la Extremadura que ya analizase Ruiz Gálvez y Galán (1991) en su momento. Celestino (2001: 75-76) no apoya la tesis de los anteriores y en los mapas de distribución que ofrece en su obra muestra cómo la hipotética ruta de las estelas atlánticas del Bronce Final se cruza con los depósitos de espadas y tienen relación directa con el mundo de la ganadería y de las cañadas. Según este autor se muestra en concentraciones personalizadas en las diferentes zonas geográficas, no como hitos aislados en un camino o vía determinada e incluso muchas estelas aparecen alejadas de los ejes principales de las vías de comunicación propuestas, lo que, en su opinión invalida la posibilidad de que las estelas señalen los principales vías de comunicación o de lugares de acceso a esas vías. A Sebastián Celestino tampoco le convence que fueran señalizadores de caminos, ya que no siempre aparecen en lugares altos que los hicieran visibles. Sin embargo, el depósito de armas que estamos estudiando se sitúa geográficamente en un lugar estratégico (cierto es que no es el más estratégico) y además existen evidencias de que pudo estar señalizado por dos afloramientos de cuarcita hoy día arrasados (Fernández 2002: 27).

Para una primera interpretación de estas piezas sería de gran ayuda evaluar cuál fue el significado y qué papel jugó el metal en estas sociedades. Durante el Bronce Final se incrementó el trasiego de ideas, de gentes, y de mercancías, entre las que los metales llegaron a circular en redes de intercambio a larga distancia. En este contexto, la Península Ibérica, especialmente su mitad occidental, rica en metales de cobre, estaño y plata, ejerce un enorme atractivo para los comerciantes extrapirenaicos, lo que influirá en la reanudación en el Bronce Final de los contactos atlánticos, interrumpidos a finales del Calcolítico (Ruiz Gálvez 1987: 261). Es de suponer que los individuos que controlaban estos intercambios de metal a larga distancia durante el Bronce Final serían la élite social, que sería la que tenía capacidad de monopolizar dichos intercambios (6). Como consecuencia se produce la llegada de nuevas ideas en cuanto a formas de armamento cada vez más especializado, como espadas (ej.: pistiliformes procedentes del área atlántica francesa) y puñales (ej.: puñales tipo Venat procedentes de este

(6) Torres Ortiz, M. 2001: Tartessos. Tesis Doctoral. 20 noviembre 2001. Universidad Complutense. Madrid. Inédita. ámbito). Otros tipos, sin embargo, se producirán en la propia Península Ibérica y se exportarán al ámbito atlántico europeo, tal y como indican el hallazgo de algunos moldes de espadas en lengua de carpa y de puñales de tipo Línea Venat (Del Amo 1983; González Prats 1992). Más allá de la importancia intrínseca de los bienes intercambiados habría que colocar el acento en la importancia de los lazos sociales que su trueque producía aunque hubiera, desde luego, algún tipo de beneficio económico.

Es obvio que en estos grupos sociales el metal en general y el bronce en particular, jugó un papel fundamental en el que su tenencia denotaba poder y otorgaba prestigio. En este momento, en el que la metalurgia se convierte en una de las actividades económicas más sobresalientes, se produce un fenómeno, no completamente novedoso, pero que llega a adquirir una notoriedad nunca antes igualada. Nos referimos a los depósitos, que proliferan en gran número en toda la Europa Atlántica (Kristiansen 1998). Sin embargo, aún es muy difícil analizar cuál era el fin último de los depósitos y diferenciar si hubo diferentes propósitos en las ocultaciones.

Las armas, eficaces en combate, también estaban destinadas a impresionar al enemigo y demostrar status económico y social. Por ello, aún nos preguntamos si realmente las espadas cortas de Puertollano fueron utilizadas con regularidad o simplemente fueron lo que se conocen como "armas de parada" de las élites del momento que fundamentalmente otorgaban prestigio y poder y se mostraban pero no se utilizaban. Si fuera así, las grietas y los dobleces de las armas serían consecuencia de su depósición en la tierra durante tres mil años. En el caso contrario de utilización, cuando se deterioraban de tal forma que no cabía una reutilización sin una refundición total, se acumulaban paulatinamente y se ocultaban para que los enemigos no pudieran darles ningún uso. Sin embargo, la presencia del puñal $n .^{\circ} 7$ y de la espada n. ${ }^{\circ} 1$, sin melladuras ni roturas que los hagan inservibles, nos provoca una duda muy razonable para seguir manteniendo esta última teoría. ¿Qué función desarrollarían estos ejemplares en un depósito para reamortizar?

El hecho de que la única espada propiamente dicha de este depósito haya aparecido fragmentada y que de la parte distal no haya aparecido quizás nos esté dando la pauta para una explicación similar a la anterior: la de que se trató de una ocultación de armas inutilizadas por el propio uso y cuya ocultación podría responder a un posible re-

T. P., 59, n. $^{\circ} 2,2002$ 
aprovechamiento futuro. En este caso deberíamos preguntarnos a qué se debe su situación, que no parece casual.

Es cierto que no todos los depósitos tienen que tener como fin servir de marcador geográfico de cualquier tipo. Sobre todo teniendo en cuenta que siendo ocultaciones no serían accesibles puesto que de otro modo perderían su carácter principal de escondrijos. Sin embargo, no dejamos de pensar en la abundancia de depósitos que se encuentran en encrucijadas de caminos, lo que debería responder a algún tipo de razón: marcadores de territorios (parecidos a las estelas, si es que estas lo fueron), deposición de materiales amortizables en lugares consabidos o tradicionalmente acordados, acuerdos entre diferentes grupos que conllevarían la deposición de las armas de los grupos vencidos en lugares también prefijados, situación similar a la de la Edad del Hierro en el Norte de Europa (Hedeager 1992).

\section{CONCLUSIONES}

En el yacimiento arqueológico de "El Camino de Santiago", localizado en las proximidades de Puertollano encontramos dos momentos de ocupación diferentes. Por un lado, los restos de cerámica y material lítico documentados en la excavación arqueológica parecen corresponder a un Calcolítico Final. Por otro, nos encontramos ante un conjunto de armas de bronce que se inscriben en el mundo del Bronce Final Atlántico.

En este último caso se trata de un depósito armamentístico terrestre, posiblemente con señalización externa, que se localiza junto a un pozo y a un arroyo y en lo que sería el paso de un cordel ganadero hacia la zona Norte de Puertollano. Además en el cercano cerro de Buenavista se localiza un yacimiento del Bronce Final. Es esta una zona hasta ahora exenta de elementos metálicos de esta época, aunque con una tradición anterior, del Bronce Pleno (espada argárica de Puertollano), que muestra un intenso poblamiento, cuyas gentes, suponemos no pudieron desaparecer repentinamente y quizás evolucionaron debido a la llegada de nuevas influencias externas (no olvidemos que la zona se sitúa en lo que se conoce como periferia del mundo tartéssico).

En este depósito de armas encontramos tres tipos de elementos ofensivos: espadas, puñales y regatón. Del primer tipo hay 9 armas inutilizadas por rotu- ra o doblez o por faltarles la empuñadura y una sóla espada en perfecto estado. En el grupo de los puñales encontramos 2 inútiles debido a la presencia de grietas en las hojas y al deterioro evidente de la parte de la empuñadura y 2 en perfecto estado. Debemos dejar patente que en sólo dos de las armas del depósito han aparecido remaches. El regatón aparece fracturado en sus extremos.

Tanto las características tipológicas de las armas que hemos presentado, como los paralelos, y la propia coherencia interna del depósito, permiten datar este conjunto en el Bronce Final III, en torno al 950 a.C.

En cuanto al propio carácter del depósito se puede descartar que se tratase de un depósito de fundidor o de un depósito clásico de mercader. Pensamos que casi todas las características nos llevan a pensar que sería un depósito ritual o votivo. Algunos aspectos refrendan mejor esta última posibilidad. Por un lado se sitúa en un paso natural que, aunque no es el más directo hacia Puertollano (sería el de la Carretera de Mestanza a Puertollano), sí es el que tiene más amplitud y por el que pasaba algún cordel de ganadería. Otro aspecto que juega a favor de esta hipótesis es que es un depósito homogéneo, en el que todas sus piezas son armamentísticas y en el que no hay mezcla de funcionalidades. El carácter general de las piezas es de corta longitud y, casualmente, las que pudieron ser mayores como el extremo de la empuñadura de la espada larga o el puñal reamortizado en la parte de la lengua de carpa de una espada, aparecen fragmentadas con dimensiones semejantes al resto del conjunto. Puesto que se repite el esquema, pensamos que es un elemento deliberado de concordancia o coherencia interna.

Son muchas las hipótesis que podrían plantearse al hilo del hallazgo de un depósito de estas características. Desde que se trate de acumulaciones realizadas por comerciantes independientes para intercambio en trueques rituales (Malinovski 1995 [1961) con otros artesanos metalúrgicos con el afán de obtener cualquier tipo de beneficio personal, hasta que se trate de comerciantes obligados a esconder los objetos para evitar su robo por otros miembros interesados de cada grupo (élites, artesanos, etc.). Sin embargo, una tercera posibilidad, y por la que más nos inclinamos, sería la de que este depósito que hemos analizado respondiera a la acumulación de las armas de los enemigos muertos o vencidos en la batalla y el lugar, el sitio de la contienda, tal y como se apuntó ya hace tiempo para la

T. P., 59, n. ${ }^{\circ} 2,2002$ 
Edad del Hierro (Hedeager 1992). De este modo cobrarían sentido aspectos como el hallazgo en el mismo depósito de armas nuevas y viejas, el lugar clave elegido para el escondrijo, etc.

\section{BIBLIOGRAFÍA}

ALMAGRO BASCH, M. 1940: El hallazgo de la ría de Huelva y el final de la Edad del Bronce en el Occidente de Europa. Ampurias 2: 85-144.

AMO, M. del 1983: "Un molde para la fabricación de espadas del Bronce Final hallado en Ronda". Homenaje al Prof. Martín Almagro Basch. II: 81-97.

BELDA, A. 1963: "Un nuevo Campo de urnas al Sur del Tajo", Ampurias XXV: 198-201.

BRIARD, J. y MOHEN, J-P. 1983: Typologie des objects de l'Age du Bronce en France. Fascicule II: Poignards, hallebardes, pointes de lance, pointes de Flèche, armement défensif. Societé Préhistorique Française. Commisión du Bronze. Paris.

CELESTINO PÉREZ, S. (2001): Estelas de guerreros y estelas diademadas. La precolonización y formación del mundo tartésico. Ed. Bellaterra Arqueología. Barcelona.

COFFYN, A. 1985: Le Bronze Final Atlantique dans la Péninsule Ibérique. París. Bocard.

COFFYN, A. GÓMEZ, J. y MOHEN, J.P. 1981: L'apogée du Bronze atlantique: le dépôt de Vénat. Paris. Picard

FERNÁNDEZ GARCÍA, S. 1997: "Los puñales 'tipo Porto de Mos' en el Bronce Final de la Península Ibérica”. Complutum 8: 97-124.

FERNÁNDEZ MANZANO, J. 1986: Bronce Final en la Meseta Norte española: el utillaje metálico. Monografías. Investigaciones Arqueológicas en Castilla-León. Soria.

FERNÁNDEZ RODRÍGUEZ, M. 2001: “La necrópolis del sector IV-E de Alarcos". Arqueología Funeraria: Las Necrópolis de incineración. Colección Humanidades, Universidad de Castilla-La Mancha, Ciudad Real. 259284.

- 2002: "El Bronce Final Atlántico en la provincia de Ciudad Real: el Depósito de Puertollano (Ciudad Real)". Revista de Arqueología, Madrid, abril 252: 24.31.

- e.p.: "Un depósito de armas del Bronce Final en Puertollano (Ciudad Real)". Actas del I Congreso de Bronce Final en la Meseta, celebrado en Molina de Aragón, Guadalajara, 2000.

GONZÁLEZ PRATS, M. 1992: “Una vivienda metalúrgica en la Peña Negra (Crevillente, Alicante)". Trabajos de Prehistoria 49: 143-147.

GONZÁLEZ ORTIZ, J. 1989a: "Pintura rupestre esquemática en la comarca de Puertollano", VII, VIII y IX Jornadas de Historia de Puertollano, Biblioteca de Auto- res Manchegos 55: 13-74.

- 1989b: "Construcciones megalíticas en la comarca de Puertollano, VII, VIII y IX Jornadas de Historia de Puertollano". Biblioteca de Autoeres Manchegos 55: 161-170.

HEDEAGER, L. 1992: Iron Age societies fron tribe to state in Nothern Europe, 500BC to AD 700. CUP. Oxford

KRISTIANSEN, K. 1998: Europe before history. CUP. Cambridge.

LÓPEZ PALOMO, L.A. 1978: Pequeño depósito de bronces en el río Genil. Cuadernos de Prehistoria de la Universidad de Granada 3: 231-244.

MALINOWSKI, B. 1995: Los Argonautas del Pacífico Occidental: un estudio sobre el comercio y aventura entre indígenas de los archipiélagos de Nueva Guinea melanésica. Barcelona. Península.

MEIJIDE CAMESELLE, G. 1988: Las espadas Bronce Final en la Península Ibérica. Arqueohistorica 1, Santiago de Compostela.

MONTERO, I. y FERNÁNDEZ, M., 2002: "Espadas y puñales del Bronce Final: El depósito de armas de Puertollano (Ciudad Real)". Gladius, XXII.

NAJERA, T. y MOLINA, F. 1977: "La edad del Bronce en La Mancha. Excavaciones en las Motillas del Azuer y Los Palacios (Campaña de 1974)". Cuadernos de Prehistoria de la Universidad de Granada 2: 251300.

PEREIRA, J. 1994: La transición del Bronce Final al Hierro en la Meseta Sur. La Edad del Bronce en CastillaLa Mancha. Actas del Simposio 1990: 37-85. Diputación Provincial de Toledo. Toledo.

RAMÍREZ MADRID, L.F. 1995: Evolución histórica de Puertollano. Ediciones Puertollano, 157.

RODRÍGUEZ DE LA ESPERANZA, M. J. 1996: "Metalurgia en la Edad del Bronce: el sur del Medio Ebro". Trabajos de Prehistoria 53 (2): 77-93.

RODRÍGUEZ DÍAZ, A. y ENRÍQUEZ NAVASCUÉS, J.J. 2001: Extremadura tartésica: Arqueología de un proceso periférico. Barcelona: Bellaterra, D.L.

ROWLANDS, M.J. 1976: The Production and Distribution of Metalwork in the Middle Bronze Age in Southern Britain. British Archaeological Reports, 31. Oxford.

RUIZ DELGADO, M. Ma 1988: "Un nuevo depósito de armas del Bronce Final en el río Guadalquivir". Trabajos de Prehistoria 45: 273-279.

RUIZ-GALVEZ PRIEGO, Mª L. 1984: La península Ibérica y sus relaciones con el Círculo Cultural Atlántico. Colección Tesis Doctorales nº139/84. Editorial Universidad Complutense.

- 1995: Ritos de Paso y Puntos de Paso. La Ría de Huelva en el Mundo del Bronce Final Europeo. Complutum, extra/5. Madrid. Servicio de publicaciones de la universidad Complutense.

- 1998: La Europa Atlántica en la Edad del Bronce: un viaje a las raices de la Europa Occidental. Ed. Crítica. Barcelona.

T. P., 59, n. $^{\circ} 2,2002$ 
RUIZ GALVEZ, Ma L. y GALÁN, E. 1991: “Las estelas del Suroeste como hitos de rutas ganaderas y vías comerciales". Trabajos de Prehistoria 48: 257-273

SÁNCHEZ, C. y GARCÍA CÁCERES, A. 1989: “Aspectos geológicos de Puertollano y su comarca". VII, VIII y IX Jornadas de Historia de Puertollano. Biblioteca de Autores Manchegos 55: 327-343.
VILASECA, F. 1993: La estela decorada y la espada de lengua de carpa del Bronce Final de Almarge-Málaga. Baetica 15: 217-226.

ZARZALEJOS, M., HEVIA, P., BORRAJO, G. y BURKHALTER, C., e.p.: "El Horizonte del Bronce Final de la Bienvenida (Almodóvar del Campo, Ciudad Real)". II Encuentros de Arqueología en Molina de Aragón. El Bronce Final en la Meseta. Molina deAragón (abril de 2001).

\section{原

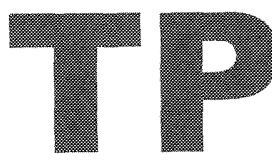 \\ TRABAJOS DE \\ PREHISTORIA \\ Departamento de Prehistoria, IH Consejo Superior de Investigaciones Científicas CSIC}

Trabajos de Prehistoria es editada por el Departamento de Prehistoria del Instituto de Historia (CSIC).

Trabajos de Prehistoria publica prioritariamente estudios sobre Prehistoria y Protohistoria de la Península Ibérica, o sobre temas europeos en relación con ésta. Se interesa por temas de sintesis, estudios interdisciplinarios, teoria y metodología arqueológicas, arqueometría y paleoambiente. Se estructura en tres secciones: Artículos de fondo, Noticiario y Reseñas.

Trabajos de Prehistoria is published biannually by the department of Prehistory, Institute of History (CSIC).

Trabajos de Prehistoria has as its first priority to publish works on the Prehistory and Protohistory of the Iberian Peninsula or on European topics related to Iberia. It stresses synthesis, interdisciplinary studies, papers on theory and method, archaeometry and palaeoenviroment. It has three sections: Articles, Reports and Book reviews.

\section{BOLETÍN DE SUSCRIPCIÓN SUBSCRIPTION FORM}

Nombre / Name

Dirección / Address

Suscripción Anual España

Fecha / Date

\section{ENVIAR A / ORDER FORM}

Departamento de Publicaciones, CSIC

C./ Vitruvio, 8. 28006 Madrid, España

Tfno.: 915612 833. Fax: 915629634

\section{$37,66 € .+$ IVA $4 \%$}

\author{
Annual Suscription Abroad
}

$55,09 €+$ IVA $4 \%$

Firma / Signature

7 Cheque bancario a nombre del Departamento de Publicaciones, CSIC Cheque payable to Departamento de Publicaciones, CSIC

Contra Reembolso / Cash on delibery
Factura pro forma / Proforma invoice

Tarjeta / Card number (Visa/4B/ Mastercard/Maestro) Fecha de caducidad Date of expiry 